\title{
Pulmonary arterial hypertension
}

David Montani $i^{1,2,3 \dagger}$, Sven Günther ${ }^{1,2,3+}$, Peter Dorfmüller ${ }^{1,2,3}$, Frédéric Perros ${ }^{1,2,3}$, Barbara Girerd ${ }^{1,2,3}$, Gilles Garcia ${ }^{1,2,3}$, Xavier Jaïs ${ }^{1,2,3}$, Laurent Savale ${ }^{1,2,3}$, Elise Artaud-Macari ${ }^{1,2,3}$, Laura C Price ${ }^{4}$, Marc Humbert ${ }^{1,2,3}$, Gérald Simonneau ${ }^{1,2,3}$ and Olivier Sitbon ${ }^{1,2,3^{*}}$

\begin{abstract}
Pulmonary arterial hypertension (PAH) is a chronic and progressive disease leading to right heart failure and ultimately death if untreated. The first classification of PH was proposed in 1973. In 2008, the fourth World Symposium on PH held in Dana Point (California, USA) revised previous classifications. Currently, PH is devided into five subgroups. Group 1 includes patients suffering from idiopathic or familial PAH with or without germline mutations. Patients with a diagnosis of PAH should systematically been screened regarding to underlying mutations of BMPR2 gene (bone morphogenetic protein receptor type 2) or more rarely of ACVRL1 (activine receptor-like kinase type 1), ENG (endogline) or Smad8 genes. Pulmonary veno occusive disease and pulmonary capillary hemagiomatosis are individualized and designated as clinical group 1'. Group 2 'Pulmonary hypertension due to left heart diseases' is divided into three sub-groups: systolic dysfonction, diastolic dysfonction and valvular dysfonction. Group 3 'Pulmonary hypertension due to respiratory diseases' includes a heterogenous subgroup of respiratory diseases like PH due to pulmonary fibrosis, COPD, lung emphysema or interstitial lung disease for exemple. Group 4 includes chronic thromboembolic pulmonary hypertension without any distinction of proximal or distal forms. Group 5 regroup PH patients with unclear multifactorial mechanisms. Invasive hemodynamic assessment with right heart catheterization is requested to confirm the definite diagnosis of $\mathrm{PH}$ showing a resting mean pulmonary artery pressure (mPAP) of $\geq 25 \mathrm{mmHg}$ and a normal pulmonary capillary wedge pressure (PCWP) of $\leq 15 \mathrm{mmHg}$. The assessment of PCWP may allow the distinction between pre-capillary and post-capillary PH (PCWP $>15 \mathrm{mmHg}$ ). Echocardiography is an important tool in the management of patients with underlying suspicion of $\mathrm{PH}$. The European Society of Cardiology and the European Respiratory Society (ESC-ERS) guidelines specify its role, essentially in the screening proposing criteria for estimating the presence of PH mainly based on tricuspid regurgitation peak velocity and systolic artery pressure (sPAP). The therapy of PAH consists of non-specific drugs including oral anticoagulation and diuretics as well as PAH specific therapy. Diuretics are one of the most important treatment in the setting of $\mathrm{PH}$ because right heart failure leads to fluid retention, hepatic congestion, ascites and peripheral edema. Current recommendations propose oral anticoagulation aiming for targeting an International Normalized Ratio (INR) between 1.5-2.5. Target INR for patients displaying chronic thromboembolic PH is between 2-3. Better understanding in pathophysiological mechanisms of PH over the past quarter of a century has led to the development of medical therapeutics, even though no cure for PAH exists. Several specific therapeutic agents were developed for the medical management of PAH including prostanoids (epoprostenol, trepoprostenil, iloprost), endothelin receptor antagonists (bosentan, ambrisentan) and phosphodiesterase type 5 inhibitors (sildenafil, tadalafil). This review discusses the current state of art regarding to epidemiologic aspects of $\mathrm{PH}$, diagnostic approaches and the current classification of PH. In addition, currently available specific PAH therapy is discussed as well as future treatments.
\end{abstract}

\footnotetext{
* Correspondence: olivier.sitbon@bct.aphp.fr

${ }^{\dagger}$ Equal contributors

'Univ. Paris-Sud, Faculté de Médecine, Kremlin-Bicêtre F-94270, France

${ }^{2} \mathrm{AP}-\mathrm{HP}$, DHU TORINO, Centre de Référence de I'Hypertension Pulmonaire

Sévère, Service de Pneumologie et Réanimation Respiratoire, Hôpital Bicêtre,

Le Kremlin-Bicêtre F-94270, France

Full list of author information is available at the end of the article
}

\section{Biomed Central}

(c) 2013 Montani et al.; licensee BioMed Central Ltd. This is an Open Access article distributed under the terms of the Creative Commons Attribution License (http://creativecommons.org/licenses/by/2.0), which permits unrestricted use, distribution, and reproduction in any medium, provided the original work is properly cited. 


\section{Definition and classification}

Pulmonary arterial hypertension (PAH) is defined by right-heart catheterization (RHC) showing precapillary pulmonary hypertension with a mean pulmonary artery pressure (mPAP) of $>25 \mathrm{mmHg}$ and a normal pulmonary artery wedge pressure (PCWP) of $<15 \mathrm{mmHg}[1,2]$. The classification of pulmonary hypertension $(\mathrm{PH})$ has gone through a series of changes since the first classification proposed in 1973 which designated only two categories, primary pulmonary hypertension or secondary $\mathrm{PH}$, depending on the presence or absence of identifiable causes or risk factors [3,4]. In 1998, a second World Symposium on $\mathrm{PH}$ was held in Evian (France) and this classification attempted to create categories of $\mathrm{PH}$ that shared similar pathogenesis, clinical features and therapeutic options [5]. This classification allowed defining homogenous groups of patients to conduct clinical trials and to obtain approval for specific PAH therapies worldwide. In 2003, the third World Symposium on PH (Venice, Italy) did not propose major changes. However, the terms idiopathic PAH, familial PAH, and associated $\mathrm{PAH}$ were introduced. The other prominent change was to move pulmonary veno-occlusive disease (PVOD) and pulmonary capillary hemangiomatosis $(\mathrm{PCH})$ from separate categories into a single subcategory of PAH.

In 2008, the fourth World Symposium on PH held in Dana Point (California, USA) and the consensus of an international group of experts was to revise previous classifications in order to accurately reflect published data, as well as to clarify some areas that were unclear. In 2013, the fifth World Symposium on PH held in Nice (France) and proposed only minor modifications, however, since the definite conclusions of this symposium were not yet published, we presented the Dana Point classification of PH (Table 1).

\section{Group 1: Pulmonary arterial hypertension}

The nomenclature of the subgroups and associated conditions has evolved since the first classification, and additional modifications were added in the Dana Point classification.

\section{Group 1.1/1.2 Idiopathic and heritable $P A H$}

Idiopathic PAH describes a sporadic disease with neither a family history of PAH nor an identified risk factor. When PAH occurs in a familial context, germline mutations in the bone morphogenetic protein receptor 2 (BMPR2) gene, a member of the transforming growth factor beta (TGF- $ß$ ) signaling family, can be detected in about $70 \%$ of cases [6,7]. More rarely, mutations in activin receptor like kinase type 1 (ACVRL1 or ALK1) or endoglin genes, also coding for members of the TGF- $\beta$ signaling family, have been identified in patients with $\mathrm{PAH}$, predominantly with coexistent hereditary hemorrhagic telangiectasia. Some authors suggested that mutations of genes encoding for Smads proteins (Smad8, Smad1 and Smad5), which are other members of the TGF- $\beta$ signaling pathway, or mutations in caveolin-1 gene may predispose to PAH [8-10].

BMPR2 mutations have also been detected in 11-40\% of apparently idiopathic cases with no family history

\section{Table 1 Diagnostic classification of pulmonary}

\section{hypertension}

\begin{tabular}{|c|c|}
\hline \multirow{11}{*}{$\begin{array}{l}\text { 1. Pulmonary arterial } \\
\text { hypertension (PAH) }\end{array}$} & 1.1 Idiopathic \\
\hline & 1.2 Heritable \\
\hline & 1.3 Drugs and toxins induced \\
\hline & 1.4 Associated with (APAH): \\
\hline & 1.4.1 Connective tissue disease \\
\hline & $\begin{array}{l}\text { 1.4.2 Infection with human } \\
\text { immunodeficiency virus }\end{array}$ \\
\hline & 1.4.3 Portal hypertension \\
\hline & 1.4.4 Congenital heart disease \\
\hline & 1.4.5 Schistosomiasis \\
\hline & $\begin{array}{l}\text { 1.4.6 Chronic haemolytic } \\
\text { anaemia }\end{array}$ \\
\hline & $\begin{array}{l}1.5 \text { Persistent pulmonary } \\
\text { hypertension of the newborn }\end{array}$ \\
\hline \multirow{3}{*}{$\begin{array}{l}\text { 2. Pulmonary hypertension with } \\
\text { left heart disease }\end{array}$} & 2.1 Systolic dysfunction \\
\hline & 2.2 Diastolic dysfunction \\
\hline & 2.3 Valvular disease \\
\hline
\end{tabular}

3. Pulmonary hypertension due 3.1 Chronic obstructive pulmonary to lung diseases and/or hypoxia disease

\begin{tabular}{|c|c|}
\hline & 3.2 Interstitial lung disease \\
\hline & $\begin{array}{l}3.3 \text { Other pulmonary diseases } \\
\text { with mixed restrictive and } \\
\text { obstructive pattern }\end{array}$ \\
\hline & 3.4 Sleep-disordered breathing \\
\hline & $\begin{array}{l}\text { 3.5 Alveolar hypoventilation } \\
\text { disorders }\end{array}$ \\
\hline & $\begin{array}{l}\text { 3.6 Chronic exposure to high } \\
\text { altitude }\end{array}$ \\
\hline & 3.7 Developmental abnormalities \\
\hline $\begin{array}{l}\text { 4. Chronic thromboembolic } \\
\text { pulmonary hypertension }\end{array}$ & \\
\hline $\begin{array}{l}\text { 5. PH with unclear and/or } \\
\text { multifactorial mechanisms }\end{array}$ & $\begin{array}{l}\text { 5.1 Haematological disorders: } \\
\text { myeloproliferative disorders, } \\
\text { splenectomy. }\end{array}$ \\
\hline & $\begin{array}{l}5.2 \text { Systemic disorders: sarcoidosis, } \\
\text { pulmonary Langerhans cell } \\
\text { histiocytosis, } \\
\text { lymphangioleiomyomatosis, } \\
\text { neurofibromatosis, vasculitis }\end{array}$ \\
\hline & $\begin{array}{l}\text { 5.3 Metabolic disorders: glycogen } \\
\text { storage disease, Gaucher } \\
\text { disease, thyroid disorders }\end{array}$ \\
\hline & $\begin{array}{l}\text { 5.4 Others: tumoral obstruction, } \\
\text { fibrosing mediastinitis, chronic } \\
\text { renal failure on dialysis }\end{array}$ \\
\hline
\end{tabular}

This classification was adapted from (Simonneau et al. [16]). 
$[11,12]$. Indeed, the distinction between idiopathic and familial PAH with BMPR2 mutations is artificial, as all patients with a BMPR2 mutation have heritable disease. In addition, BMPR2 mutations were identified in only 70-80\% families with PAH. Thus, it was decided to abandon the term "familial PAH" in favor of the term "heritable PAH", including idiopathic PAH with germline mutations and familial cases with or without identified mutations $[13,14]$.

\section{Group 1.3 Drug- and toxin-induced PAH}

A number of risk factors for the development of PAH have been individualized in the last European Respiratory Society/ European Society of Cardiology (ERS/ESC) conjoint guidelines of $\mathrm{PH}$ [15] (Table 2).

Aminorex, fenfluramine derivatives and toxic rapeseed oil represent the only identified "definite" risk factors for $\mathrm{PAH}[5,16]$. Souza et al. have demonstrated that this subgroup of $\mathrm{PAH}$ shares clinical, functional, hemodynamic, and genetic features with idiopathic $\mathrm{PAH}$, suggesting that fenfluramine exposure represents a potential trigger for PAH without influencing its clinical course [17].

Two prospective epidemiologic investigations, the SNAP (Surveillance of North American Pulmonary Hypertension) and the SOPHIA (Surveillance of Pulmonary Hypertension

Table 2 Updated risk level of drugs and toxins known to be associated with PAH

\begin{tabular}{|c|c|}
\hline \multicolumn{2}{|l|}{ 1. Definite } \\
\hline & Aminorex \\
\hline & Fenfluramine \\
\hline & Dexfenfluramine \\
\hline & Toxic rapeseed oil \\
\hline & Benfluorex \\
\hline \multicolumn{2}{|l|}{ 2. Likely } \\
\hline & Amphetamines \\
\hline & L-tryptophan \\
\hline & Metamphetamines \\
\hline & Dasatinib \\
\hline \multicolumn{2}{|l|}{ 3. Possible } \\
\hline & Cocaine \\
\hline & Phenylpropanolamine \\
\hline & St John's Wort \\
\hline & Chemotherapeutic agents \\
\hline & Selective serotonin reuptake inhibitors \\
\hline & Pergolide \\
\hline \multicolumn{2}{|l|}{ 4. Unlikely } \\
\hline & Oral contraceptives \\
\hline & Estrogen therapy \\
\hline & Cigarette smoking \\
\hline
\end{tabular}

*This table was adapted from Galiè et al. [15]. in America) study, were conducted in the USA $[18,19]$. These investigations included retrospectively 559 and 1335 patients with $\mathrm{PH}$, respectively, and confirmed the previously described association between idiopathic PAH and the use of fenfluramine. In the SNAP study, the odds ratio of developing $\mathrm{PH}$ was 7.5 for the use of fenfluramine more than six months of treatment [18].

The agent benfluorex is structurally and pharmacological related to fenfluramine and may be also considered as an anorectic agent. Frachon and co-workers [20] showed a significantly higher prevalence of unexplained valvular heart disease in patients taking benfluorex compared to controls. In addition, Savale and co-workers demonstrated recently that exposure to benfluorex is suggested to be a trigger in the development of PAH [21]. Benfluorex was withdrawn from the market in 2009.

The SOPHIA study examined intake of a variety of nonselective monoamine reuptake inhibitors, selective serotonin reuptake inhibitors, antidepressants and anxiolytics. No increased risk of developing PAH was observed [19].

Amphetamine use represents a "likely" risk factor, although they are frequently used in combination with fenfluramine. A recent retrospective study suggested a relationship with the use of methamphetamine (inhaled, smoked, oral, or intravenous) and the occurrence of $\mathrm{PAH}$ [22]. Methamphetamine use is now considered a "very likely" risk factor for the development of PAH.

Recently published data from the French registry of pulmonary hypertension suggested that dasatinib, a tyrosine kinsase inhibitor (TKI), may induce precapillary $\mathrm{PAH}$ [23]. Several cases of precapillary $\mathrm{PH}$ in chronic myelogenous leukemia patients treated with dasatinib have been reported.

\section{Group 1.4.1 PAH associated with connective tissue diseases}

$\mathrm{PAH}$ associated with connective tissue diseases (CTD) represents an important clinical subgroup, in which systemic sclerosis represents the major cause of CTD associated PAH. The prevalence of PAH has been well established only for systemic sclerosis (SSc). Prospective studies using echocardiography as a screening method and $\mathrm{RHC}$ for confirmation found a prevalence of $\mathrm{PAH}$ between 7-12\% [24,25]. PH due to lung fibrosis [26], diastolic left heart dysfunction [27] and primary cardiac involvement [28] are also frequent in the setting of pulmonary hypertension in these patients, emphasizing the importance of a systemic evaluation with RHC to accurately classify the underlying mechanism of $\mathrm{PH}$.

\section{Group 1.4.2 HIV infection}

$\mathrm{PAH}$ is a rare complication of HIV infection [29,30]. HIV-associated PAH has clinical, hemodynamic, and 
histologic characteristics broadly similar to those seen in idiopathic PAH. Epidemiologic data in the early 1990s, a time when therapy with highly active antiretroviral therapy was not yet available, indicated a prevalence of $0.5 \%$ [31]. The prevalence of HIV-associated PAH was evaluated more recently and showed a stable prevalence of $0.46 \%$ [32].

\section{Group 1.4.3 Porto-pulmonary hypertension}

Porto-pulmonary hypertension (POPH) is defined by the development of $\mathrm{PAH}$ associated with increased pressure in the portal circulation $[33,34]$. Prospective hemodynamic studies have shown that $2-6 \%$ of patients with portal hypertension had $\mathrm{PH}[35,36]$. However, RHC is mandatory for the diagnosis of portal $\mathrm{PH}$, as several mechanisms may increase pulmonary artery pressure in the setting of advanced liver disease: hyperdynamic circulatory state with high cardiac output, fluid overload and diastolic dysfunction. Pulmonary vascular resistance (PVR) is usually normal in these cases.

\section{Group 1.4.4 Congenital heart diseases}

A significant proportion of patients with congenital heart disease (CHD), in particular those with systemicto-pulmonary shunts, will develop PAH if left untreated. Eisenmenger's syndrome is defined as CHD with an initial large systemic-to-pulmonary shunt that induces progressive pulmonary vascular disease and $\mathrm{PAH}$, with resultant reversal of the shunt and central cyanosis $[37,38]$. It represents the most advanced form of PAH associated with CHD. It has been reported that a large proportion of patients with $\mathrm{CHD}$ develop some degree of PAH [39-41]. The prevalence of PAH associated with congenital systemic-to-pulmonary shunts in Europe and North America has been estimated between 1.6 and 12.5 cases per million adults, with $25-50 \%$ of this population affected by Eisenmenger's syndrome.

\section{Group 1.4.5 Schistosomiasis}

In the Dana Point classification, $\mathrm{PH}$ associated with schistosomiasis was included in Group 1. Recently, it has been demonstrated that $\mathrm{PH}$ associated with schistosomiasis may have a similar clinical presentation and histological findings as idiopathic PAH [42,43]. The mechanism of PAH in patients with schistosomiasis is probably multifactorial including portal $\mathrm{PH}$, a frequent complication of this disease [44] and local vascular inflammation, whereas mechanical obstruction by schistosoma eggs seems to play a minor role. More than 200 million people are infected and $4-8 \%$ of them will develop hepatosplenic disease. Then, PAH associated with schistosomiasis represents a frequent form of $\mathrm{PAH}$ in countries where the infection is endemic. Data from a recent study based on invasive hemodynamics evidenced the prevalence of $\mathrm{PAH}$ in patients with hepatosplenic disease of $4.6 \%$; also important was the prevalence of post-capillary hypertension (3\%) reinforcing the need of invasive hemodynamics for the specific diagnosis of PAH in schistosomiasis [45].

\section{Group 1.4.6 Chronic hemolytic anemia}

The chronic hemolytic anemias represent a subcategory of $\mathrm{PAH}$. There has been increasing evidence that PAH is a complication of chronic hereditary and acquired hemolytic anemias, including sickle cell disease [46,47], thalassemia [48], hereditary spherocytosis [49], stomatocytosis [50], and microangiopathic hemolytic anemia [51].

$\mathrm{PH}$ has been reported most frequently in patients with sickle cell disease, however the prevalence of $\mathrm{PAH}$ is not yet clearly established. The prevalence of $\mathrm{PH}$ in sickle cell disease is undoubtedly much lower than $32 \%$ as suggested by echocardiography [47]. Recently, a prospective epidemiologic studies using echocardiographic screening and direct hemodynamic confirmation were conducted in 398 outpatients with sickle cell disease at referral centers in France [52]. In this study, the prevalence of a tricuspid regurgitant jet velocity of at least $2.5 \mathrm{~m}$ per second measured by echocardiography was $27 \%$. In contrast, the prevalence of pulmonary hypertension confirmed on catheterization was only $6 \%$, suggesting that echocardiographic evaluation alone had a low positive predictive value for $\mathrm{PH}$ in this population. Indeed, the precise mechanism of $\mathrm{PAH}$ in sickle cell disease remains uncertain.

\section{Group 1': Pulmonary veno-occlusive disease and/or pulmonary capillary hemangiomatosis}

PVOD and $\mathrm{PCH}$ are uncommon conditions, but they are increasingly recognized as causes of $\mathrm{PH}$ [53]. A recent clinicopathologic study [54] analyzed specimens from 35 patients diagnosed as having either PVOD $(n=30)$ or $\mathrm{PCH}(\mathrm{n}=5)$. PCH was identified in $24(73 \%)$ cases diagnosed as PVOD. Indeed, venous involvement was present in 4/5 cases initially diagnosed as $\mathrm{PCH}$. These findings suggest that $\mathrm{PCH}$ may be an angioproliferative process frequently associated with PVOD. Similarities in pathologic features and clinical presentation suggest that these disorders may be two different presentation of the same disease [54].

Although PVOD and PCH may present similarly to idiopathic $\mathrm{PAH}$, there are a number of important differences. These include the presence of crackles on examination, radiologic abnormalities on high-resolution computed tomography of the chest (ground glass opacities, septal thickening, mediastinal adenopathy) [55-58], hemosiderin-laden macrophages on bronchoalveolar lavage [59], and a lower DLCO and $\mathrm{PaO}_{2}$ in patients with 
PVOD or PCH [58]. PVOD/PCH remains a difficult disorder to categorize, as it shares characteristics with idiopathic PAH but also has a number of distinct differences. Given the current evidence, it was decided that PVOD/PCH should be a distinct category but not completely separated from $\mathrm{PAH}$ and $\mathrm{PVOD} / \mathrm{PCH}$ are designated as 1 ' in the current classification.

\section{Group 2: Pulmonary hypertension due to left heart disease}

Left-sided ventricular or valvular diseases may produce an increase of left atrial pressure, leading to a backward transmission of the pressure and a passive increase of pulmonary arterial pressure. Left heart disease, probably represents the most frequent cause of $\mathrm{PH}[60]$. In this situation, PVR is normal or near normal $(<3.0$ Wood units) and there is no gradient between mean PAP and pulmonary wedge pressure (transpulmonary gradient $<12 \mathrm{~mm} \mathrm{Hg}$ ). In the Dana Point classification, the increasing recognition of left-sided heart dysfunction with preserved ejection fraction leads to changes in the subcategories of Group 2 and now this group include three distinct etiologies: left heart systolic dysfunction, left heart diastolic dysfunction, and left heart valvular disease. In some patients with left heart disease, the elevation of pulmonary arterial pressure is out of proportion to that expected from the elevation of left arterial pressure (transpulmonary gradient $>12 \mathrm{~mm} \mathrm{Hg}$ ), and PVR is increased to $>3.0$ Wood units (19-35\% of patients) [60]. However, there is no widely accepted hemodynamic definition of transpulmonary gradient, and future recommendations may propose new definition and threshold of this gradient. Some patients with left heart valvular disease or even left heart dysfunction can develop severe $\mathrm{PH}$ of the same magnitude as that seen in PAH [61-63]. The elevation of PAP and PVR may be due to either the increase of pulmonary artery vasomotor tone and/or pulmonary vascular remodeling $[64,65]$.

\section{Group 3: Pulmonary hypertension due to lung diseases and/or hypoxia}

In this group, the predominant cause of $\mathrm{PH}$ is alveolar hypoxia as a result of either chronic lung disease, impaired control of breathing, or residence at high altitude. However, the precise prevalence of $\mathrm{PH}$ in all these conditions remains largely unknown. In the revised classification, the heading has been modified to reinforce the link with the development of PH. A category of lung disease characterized by a mixed obstructive and restrictive pattern was added, including chronic bronchiectasis, cystic fibrosis and the recently described syndrome of combined pulmonary fibrosis and emphysema in which the prevalence of $\mathrm{PH}$ is almost $50 \%[66,67]$. In PAH associated with parenchymal lung disease, the increase of pulmonary arterial pressure is usually modest (mean PAP lower than $35 \mathrm{mmHg}$ ) [68]. Interestingly, in some patients, increase of PAP is out of proportion and be higher than $35 \mathrm{mmHg}$ [69]. In a retrospective study of 998 patients with chronic obstructive pulmonary disease who underwent $\mathrm{RHC}$, only $1 \%$ had severe $\mathrm{PH}$ [70]. These patients with more severe $\mathrm{PH}$ were characterized by mild-to-moderate airway obstruction, severe hypoxemia, hypocapnia, and a very low diffusing capacity for carbon monoxide.

\section{Group 4: Chronic thromboembolic pulmonary hypertension}

Chronic thromboembolic pulmonary hypertension $(\mathrm{CTEPH})$ was included in Group 4. The incidence of CTEPH is uncertain. CTEPH represents however a frequent cause of $\mathrm{PH}$ and occurs in up to $4 \%$ of patients after an acute pulmonary embolism $[71,72]$. In the classification from the third World Symposium on $\mathrm{PH}$, CTEPH was divided into 2 subgroups: proximal CTEPH and distal CTEPH, depending on the feasibility of performing pulmonary thromboendarterectomy. Currently, there is no consensus about the definitions of proximal and distal CTEPH and the decision of surgery may vary depending on individual centers [73]. Thus, the Dana Point Classification propose only one group irrespectively of proximal or distal obstruction. Patients with suspected or confirmed CTEPH need to be referred to expert centers with experience in the management of $\mathrm{CTEPH}$, to consider the feasibility of performing surgery. The indication for surgery depends on the location of the obstruction, the correlation between hemodynamics and the degree of obstruction assessed by angiography, comorbidities, the willingness of the patient, and the experience of the surgeon $[74,75]$. Patients who are not candidates for surgery may benefit from PAH-specific medical therapy [76,77]; however, further evaluation of these therapies in randomized control trials are needed [78].

\section{Group 5: PH with unclear or multifactorial etiologies Group 5.1 Hematologic disorders}

$\mathrm{PH}$ has been reported in chronic myeloproliferative disorders including polycythemia vera, essential thrombocythemia, and chronic myeloid leukemia [79,80]. Several mechanisms may be implicated in $\mathrm{PH}$ associated with chronic myeloproliferative disorders including high cardiac output, asplenia, direct obstruction of pulmonary arteries by circulating megakaryocytes [81], CTEPH [82], portal $\mathrm{PH}$, and congestive heart failure. Splenectomy as a result of trauma or as a treatment for hematologic disorders may increase the risk of developing $\mathrm{PH}$ [83]. As described above, dasatinib use may be one cause of $\mathrm{PAH}$, particularly in chronic myeloid leukemia [23]. 


\section{Group 5.2 Systemic disorders}

The second subgroup includes systemic disorders, including sarcoidosis, pulmonary Langerhans cell histiocytosis, lymphangioleiomyomatosis, neurofibromatosis or vasculitis.

$\mathrm{PH}$ is a well recognized complication of sarcoidosis [84], with a reported prevalence of $1-28 \%$ [84]. $\mathrm{PH}$ is multifactorial and usually attributed to the destruction of capillary bed by the fibrotic process and/or the result of chronic hypoxemia [85]. However, the severity of $\mathrm{PH}$ is frequently out of proportion to the degree of parenchymal lung disease and blood gas abnormalities, suggesting specific pulmonary vascular involvement [86]. Such mechanisms may include extrinsic compression of large pulmonary arteries by lymph node enlargement, and granulomatous infiltration of the pulmonary vasculature, especially the pulmonary veins, which sometimes mimic PVOD [87].

Pulmonary Langerhans cell histiocytosis is an uncommon cause of infiltrative and destructive lung disease. Severe $\mathrm{PH}$ is a common feature in patients with end stage disease [88] and $\mathrm{PH}$ in these patients is usually related to chronic hypoxemia and/or abnormal pulmonary mechanics. Histopathologic examination has shown severe diffuse pulmonary vasculopathy involving predominantly intralobular pulmonary veins and, to a lesser extent, muscular pulmonary arteries [89].

Lymphangioleiomyomatosis is a rare multisystem disorder predominantly affecting women, characterized by cystic lung destruction, lymphatic abnormalities, and abdominal tumors. $\mathrm{PH}$ is relatively uncommon in patients with lymphangioleiomyomatosis [90]. Recently, a series of 20 cases of lymphangioleiomyomatosis associated $\mathrm{PH}$ has been reported showing that $\mathrm{PH}$ is usually moderate in this setting and associated with pulmonary function impairment [91].

Neurofibromatosis type 1, also known as von Recklinghausen's disease, is an autosomal-dominant disease. The disease is occasionally complicated by systemic vasculopathy. A series of cases of $\mathrm{PH}$ have been reported in the setting of Neurofibromatosis type-1 [92].

\section{Group 5.3 Metabolic disorders}

$\mathrm{PH}$ has been reported in a few cases of type Ia glycogen storage disease, a rare autosomal-recessive disorder caused by a deficiency of glucose-6-phosphatase [93-95]. The mechanisms of $\mathrm{PH}$ are uncertain but portocaval shunts, atrial septal defects, severe restrictive pulmonary function defects or thrombosis are thought to play a role. In one case, autopsy findings revealed the presence of plexiform lesions [96].

Gaucher's disease is a rare disorder characterized by a deficiency of lysosomal B glucosidase, which results in an accumulation of glucocerebroside in reticuloendothelial cells. In a study of 134 patients with Gaucher's disease who were systematically screened by echocardiography, $\mathrm{PH}$ was not uncommon [97]. In this setting, several potential mechanisms for $\mathrm{PH}$ have been suggested, including interstitial lung disease, chronic hypoxemia, capillary plugging by Gaucher cells and splenectomy [97,98].

The association between thyroid diseases and $\mathrm{PH}$ has been reported in some studies [99]. A prospective study of 63 consecutive adult patients with PAH found a prevalence of autoimmune thyroid disease, including both hypothyroidism and hyperthyroidism, in 49\%, suggesting that these conditions may share a common immunogenetic susceptibility [100].

\section{Group 5.4 Miscellaneous conditions}

The last subgroup includes a number of miscellaneous conditions, including tumoral obstruction, fibrosing mediastinitis or chronic renal failure on dialysis.

A progressive obstruction of proximal pulmonary arteries leading to PH may be observed in tumor obstruction when a tumor grows into the central pulmonary arteries with additional thrombosis. Such cases are due principally to pulmonary artery sarcomas, which occur rarely but are usually rapidly fatal [101-103]. The differential diagnosis with CTEPH can be difficult and CT angiography may be useful to differenciate an obstruction by tumor or thrombotic material. Occlusion of the microvasculature by metastatic tumor emboli represents a cause of rapidly progressive $\mathrm{PH}$.

Fibrosing mediastinitis have been mainly reported in sarcoidosis, tuberculosis, histoplasmosis and after radiotherapy. Fibrosing mediastinitis may be associated with severe $\mathrm{PH}$ due to compression of both pulmonary arteries and veins.

Lastly, PH has been reported in patients with end-stage renal disease maintained on long-term hemodialysis. Based on echocardiographic studies, the prevalence of $\mathrm{PH}$ in this patient population is estimated up to 40\% [104]. $\mathrm{PH}$ in these patients may be explained by high cardiac output (resulting from the arteriovenous access, anemia and fluid overload) and potential diastolic and systolic left heart dysfunctions. Furthermore, hormonal and metabolic modification associated with end-stage renal disease might lead to dysfunction of normal pulmonary vascular tone.

\section{Epidemiology}

Information relative to the natural history of PAH was derived from a national registry conducted in the USA in the early 1980s, which included 187 patients with idiopathic PAH followed for up to 5 years. This study characterized the disease and confirmed its poor prognosis with a median survival of 2.8 years $[105,106]$. Better understanding of pathophysiological mechanisms of $\mathrm{PAH}$ has led to the development of novel therapeutic 
strategies in the last decade which improved quality of life, exercise capacity and survival of these $\mathrm{PH}$ patients [107].

In France, a national multicenter registry prospectively collected data from 674 adults with PAH from October 2002 to October 2003 and followed these patients during a 3-year period [108]. This prospective study has shown more up to date data on the epidemiology of PAH. This registry has confirmed the female predominance in most subtypes of PAH with a female/male sex ratio (SR) of 1.9 for all PAH patients, and particularly in idiopathic PAH (SR 1.6), familial PAH (SR 2.2) and anorexigenassociated PAH (SR 14.9) [108]. The mean age of PAH patients in this cohort was 50 years with a quarter of patients older than 60 years underlining the possibility of developing $\mathrm{PAH}$ in all ages. In this assessed cohort, $39.2 \%$ of patients had idiopathic PAH and 3.9\% familial $\mathrm{PAH}$. In the subgroup of $\mathrm{PAH}$, where $\mathrm{PAH}$ was associated with other conditions, $15.3 \%$ had connective tissue disease, $11.3 \%$ congenital heart diseases, $10.4 \%$ portal hypertension, 9.5\% anorexigen-related PAH and 6.2\% HIV infection [108]. In France, the low estimation of the prevalence of PAH and idiopathic PAH are respectively of 15 cases and 5.9 cases/million adult inhabitants. The low estimation of PAH incidence is 2.4 cases/million adult inhabitants/year. This study conducted five years after the withdrawal of fenfluramine derivatives underlines that anorexigen-associated PAH remains an important medical problem nowadays.

Recent prospective data in consecutive patients with idiopathic, familial or anorexigen-associated PAH patients followed-up for a period of three years (56 incident and 298 prevalent cases) showed better survival rates than historical cohort. For incident cases, estimated survival rates were $85.7 \%, 69.6 \%$ and $54.5 \%$ at one, two and three year of follow-up, respectively. In combined

\section{Table 3 Modified New York Heart Association (NYHA)} classification for pulmonary hypertension

\begin{tabular}{ll}
\hline CLASS I & Patients with pulmonary hypertension but without \\
& resulting limitation of physical activity. Ordinary physical \\
& activity does not cause undue dyspnoea or fatigue, chest \\
& pain, or near syncope. \\
\hline CLASS II & Patients with pulmonary hypertension resulting in slight \\
& limitation of physical activity. They are comfortable at rest. \\
& Ordinary physical activity causes undue dyspnoea or \\
& fatigue, chest pain, or near syncope. \\
\hline CLASS III & Patients with pulmonary hypertension resulting in marked \\
& limitation of physical activity. They are comfortable at rest. \\
& Less than ordinary activity causes undue dyspnoea or \\
& fatigue, chest pain, or near syncope. \\
\hline CLASS IV & Patients with pulmonary hypertension with inability to \\
& carry out any physical activity without symptoms. These \\
& patients manifest signs of right heart failure. Dyspnoea \\
and/or fatigue may even be present at rest. Discomfort is \\
increased by any physical activity.
\end{tabular}

mixed population (incident patients and prevalent patients diagnosed within three years before study entry), estimated one, two and three year survival was $82.9 \%$, $67.1 \%$ and $58.2 \%$, respectively. Parameters significantly associated to improved survival were female gender, preserved 6-MWD and normal cardiac output on RHC [109].

Data from the REVEAL registry (US Registry to Evaluate Early and Long-Term PAH Disease Management) are similar concerning the one year survival rate estimated to $91 \%$. Variables independently associated with increased mortality included pulmonary vascular resistance $>32$ Wood units, NYHA functional class IV, men older than 60 years and familiy history of PAH [110].

\section{Genetics}

It is now well known that PAH can be either sporadic or clustered in families [111-114]. In 1954, Dresdale published a detailed description of a family that included three related subjects with severe PAH of unknown aetiology. Because of physician's awareness of the familial occurrence of the disease, other cases of familial PAH were described. The National Institute of Health Registry (NIH Registry) provided the first estimate of this condition, and evaluated that at least $6 \%$ of individuals diagnosed with sporadic PAH have a family history of the disorder. In the French PAH registry, 26 cases of familial $\mathrm{PAH}$ were identified in the cohort of 674 patients, which corresponds to a prevalence of $3.9 \%$ of all cases of PAH and a proportion of $7.3 \%$ of familial PAH in the subgroup of idiopathic, familial or anorexigen-associated PAH [108]. Studies of genealogies of familial PAH advanced our understanding that the disease segregates an autosomal dominant trait with a markedly reduced penetrance, since only $10-20 \%$ of necessary carriers of the mutation will develop PAH $[115,116]$. In 2000, linkage analysis in PAH affected families found mutations within the bone morphogenetic protein receptor type 2 gene (BMPR2) [117,118]. BMPR2 gene encodes for a type 2 receptor member of the transforming growth factor beta (TGF- $\beta$ ) family. Nowadays, germline BMPR2 mutations are detected in $58-74 \%$ of PAH patients with a family history of the disease, and in $3.5-40 \%$ of so called idiopathic PAH patients $[6,11,108,119-123]$. The observation of the development of PAH in patients displaying hereditary hemorrhagic telangiectasia (HHT), an autosomal dominant vascular dysplasia, allowed us to identify two other PAH predisposing genes: ACVRL1 (Activin A receptor type II-like kinase 1) and ENG (endoglin) genes. Mutations in these two genes are infrequent in $\mathrm{PAH}$ but are frequently identified in HHT [120,124-130]. Moreover, recent reports described two PAH patients carriers of a mutation in Smad8 gene, one PAH patient carrier of a Smad1 mutation and one PAH 
patient carrier of a Smad5 mutation [8,9]. BMPR2 gene, ACVRL1, ENG, Smad8, Smad1 and Smad5 genes are encoding proteins which are involved in the TGF- $\beta$ signaling pathway. More recently, using whole exome sequencing in a large PAH family, Austin et al. demonstrated the involved of mutations in caveolin-1 gene in the development of $\mathrm{PAH}$ [10] They confirmed their findinds identifying a caveolin-1 mutation in an unrelated PAH patient. Caveolin-1 protein is necessary for the formation of calveola, which are crucial for joining membrane receptors and initiating cellular signaling cascade such as TGF- $\beta$ signalling pathway. This supports the hypothesis that mutations in genes involved in the TGF- $\beta$ signaling pathway may be a trigger for pulmonary vascular remodeling. Moreover, this signaling pathway controls growth, differentiation and apoptosis of various cell types like pulmonary vascular endothelial cells (ECs) and smooth muscle cells (SMCs). Thereby, mutations in genes involved in the TGF- $\beta$ signaling pathway may be responsible for abnormal proliferation of pulmonary vascular SMCs and may promote ECs apoptosis, which might lead to the selection of apoptosis resistant cells and formation of plexiform lesions, the hallmark of idiopathic PAH [131,132].

The analysis of clinical, functional and hemodynamic characteristics of $\mathrm{PAH}$ patients revealed that patients carriers of a BMPR2 or an ACVRL1 mutation are younger at diagnosis than patients with idiopathic PAH. In addition, they have more severe hemodynamic parameters at diagnosis $[114,120]$.

Several lines of evidence point to the potential requirement of additional factors, either environmental or genetic, in the pathogenesis of the disease. As mentioned, Humbert and co-workers have shown that exposure to fenfluramine derivatives greatly increase the risk of developing severe PAH in patients with $B M P R 2$ mutations [111]. Moreover, modified genes could participate or facilitate the development of PAH. In fact, recent studies have suggested the potential role of serotonin transporters, serotonin receptors, potassium channels, or angiopoietin-1 [133]. Finally, PAH mostly occurs in females irrespective of BMPR2 mutation status [134]. To explain overrepresentation of $\mathrm{PAH}$ female patients, it was suggested that estrogen metabolism might participate in the pathogenesis of PAH $[135,136]$.

\section{Pathophysiology}

$\mathrm{PAH}$ is a disease which affects small pulmonary arteries. It is characterized by vascular obstruction leading to progressive increase in vascular resistance. This increases right ventricular afterload and consequently results in right ventricular failure. Intima and media proliferation and its consequent pulmonary vascular obstruction are considered to be the key element in the pathogenesis of PAH. Vasoconstriction, vascular remodeling and thrombosis are factors that increase pulmonary vascular resistance in PAH [107,137]. These processes involve a multitude of cellular and molecular elements (Figure 1).

\section{Cellular factors}

Proliferation of smooth muscular cells in the small peripheral pulmonary arteries is a common characteristic in all forms of PAH. In hypoxic models, fibroblasts of the adventitia migrate to the media and intima, where proliferation and production of matrix proteins are observed [138]. Neovascularization, mainly of the adventitia, occurs concomitantly to the thickening of the vascular walls [139].

In response to certain stimuli, endothelial cells abnormally proliferate to form plexiform lesions in several forms of PAH. Plexiform lesions consist of endothelial cells, matrix proteins and fibroblasts and obliterate the vascular lumen [140]. The stimuli for endothelial proliferation is still unknown but several factors have been incriminated such as hypoxia, inflammation, shear stress, drugs, viral infections and genetic susceptibility. Extrapulmonary cells may also participate in the vascular remodeling responsible for $\mathrm{PAH}$. Indeed, fibrocytes and c-kit + cells are mobilized from the bone marrow, and may differentiate into vascular cells and/or produce proangiogenic factors to participate in the pathogenesis of PAH [141,142]. The CXCL12/CXCR4 axis may play an important role in the pulmonary recruitment of these circulating progenitors and can be therapeutically targeted [143].

Inflammatory mechanisms seems to play an important role in certain forms of PAH such as PAH associated with auto immune diseases or HIV infection [144]. In fact, in severe cases of $\mathrm{PAH}$ associated with systemic lupus erythematosus disease, some patients improved both clinically and hemodynamically with administrated immunosuppressant treatment. Thirty to $40 \%$ of patients with PAH have circulating auto-antibodies and elevated plasma concentrations of pro-inflammatory cytokines such as interleukin 1 (IL-1) and interleukin-6 (IL-6), and chemokines such as fractalkine and MCP-1 [145,146]. Inflammatory cells, such as lymphocytes $\mathrm{B}$ and $\mathrm{T}$, macrophages, mastocytes and dendritic cells, can also be found in plexiform lesions of severe PAH [147,148]. Chemokines, like RANTES and fractalkine are also overly expressed in the pulmonary vascular endothelium of PAH patients [145].

Thrombosis and platelet dysfunction can be important in the development of PAH. Abnormalities of thrombosis, endothelial cells or platelets can generate or aggravate thrombosis in situ. Elevated plasma concentrations of D-dimers and fibrinopeptides $\mathrm{A}$ and $\mathrm{B}$, in certain 


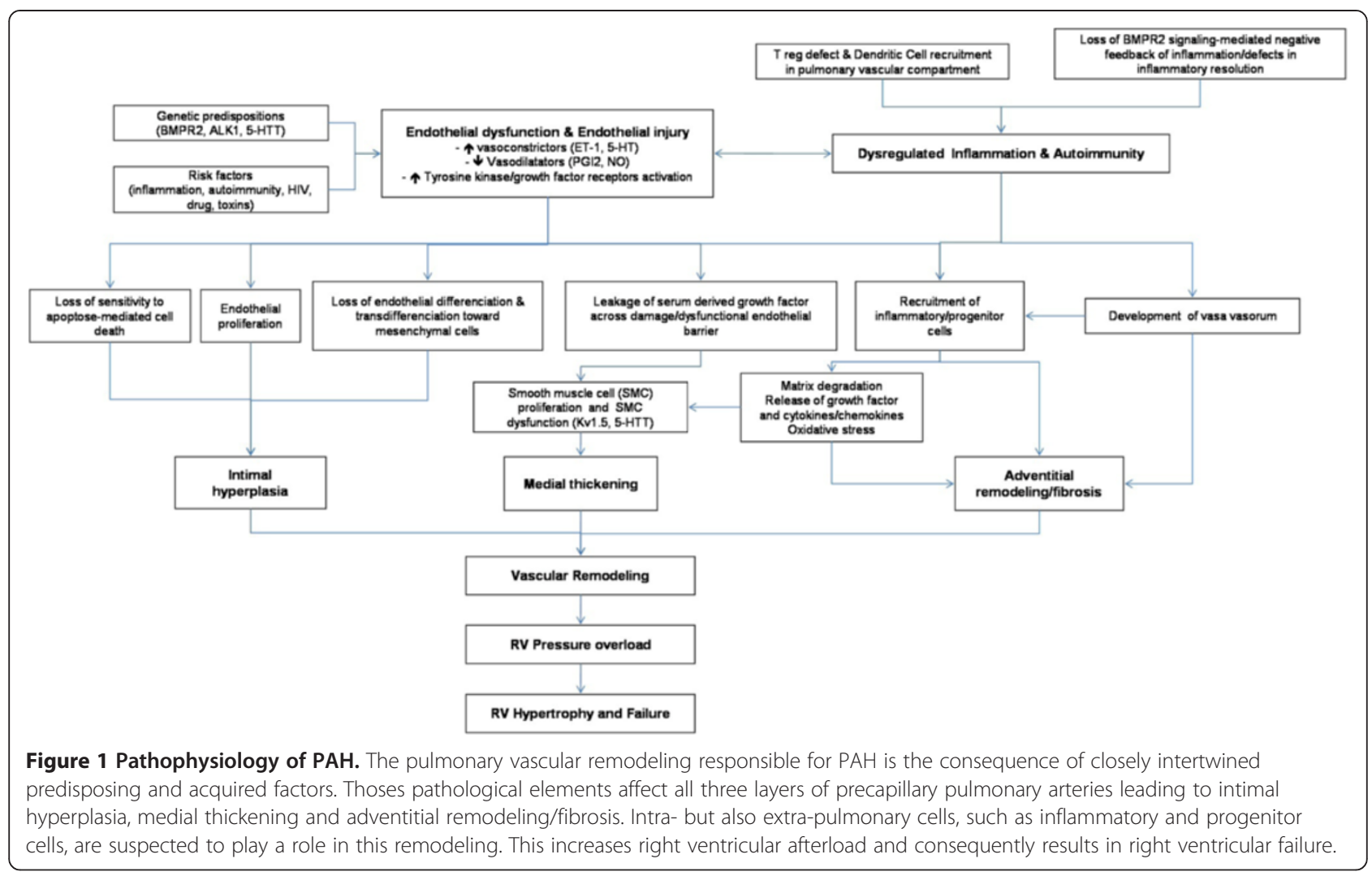

patients with $\mathrm{PAH}$, are the proof of an abnormal intravascular coagulation process. Elevated plasma concentrations of von-Willebrand factor and plasminogen activator inhibitor type 1 also reflect endothelial dysfunction in PAH. It has been demonstrated that shear stress creates pro-thrombotic vascular lesions in $\mathrm{PAH}$ that may lead to thrombosis in situ. But platelet function is not limited to coagulation. In response to certain stimuli, platelets can produce prothrombotic, vasoactive or mitogenic factors, such as thromboxane A2 (TXA2), platelet-derived growth factor (PDGF), serotonin (5hydroxytryptamine, 5-HT), transforming growth factor beta (TGF- $\beta$ ) and vascular endothelial growth factor (VEGF) that participate in vasoconstriction and vascular remodeling $[149,150]$.

\section{Autoimmunity and PAH}

The self-tolerance is controlled in the periphery by a particular population of T-lymphocytes called regulatory T-lymphocytes (Treg). The breakdown of self-tolerance can lead to the development of an autoimmune response (i.e. directed against self antigens) that can finally give rise to an autoimmune disease. Huertas et al. [151] showed that circulating Treg number was comparable in idiopathic PAH and SSc-PAH patients. However the percentage of those expressing leptin receptors was higher in idiopathic PAH and SSc-PAH as compared to controls, and their function was reduced in idiopathic $\mathrm{PAH}$ and SSc-PAH patients as compared to controls in a leptin-dependent manner [151]. Work on chronic inflammatory disorders and autoimmune diseases suggest that pathogenic antibodies and $\mathrm{T}$ cells may be generated locally, in the targeted organ, in highly organized ectopic lymphoid follicles commonly called tertiary lymphoid tissues. Recently, Perros et al. [152] described the presence of highly organized perivascular follicles in idiopathic PAH lungs arguing for specific immune-adaptive mechanisms in the pathophysiology of the disease. One can propose that deregulated and unresolved pulmonary inflammation on the background of a genetic predisposition, could result in persisting vascular remodelling leading to PAH. An initial acute inflammation that is normally expected to resolve with return to homeostasis, could conduct the production of auto-antibodies against vascular wall components, and would shift to chronic persisting and chronic inflammation, endothelial barrier breakdown, infiltration by immune cells, local and chronic autoimmunity, and vascular remodeling culminating in $\mathrm{PAH}$.

\section{Molecular factors}

Many authors consider pulmonary vasoconstriction as an early event in the process of PAH. Vasoconstriction has been associated with an abnormal function or 
expression of potassium channels and with endothelial dysfunction [107]. Endothelial dysfunction results in a decreased production of vasodilators such as nitric oxide (NO) and prostacyclin and an increased production of vasoconstrictors such as endothelin-1 [153].

Prostacyclin (prostaglandin I2) is a potent pulmonary vasodilator that acts via the cyclic adenosine monophosphate (cAMP) pathway. It inhibits the proliferation of smooth muscle cells and decreases platelet aggregation. Production of prostacyclin is reduced in endothelial cells of patients with PAH [154]. PAH therapy based on prostacyclin and its derivates have proven efficacy both hemodynamically and in clinical trials. NO is also a pulmonary vasodilator which acts via the cyclic guanosine monophosphate (cGMP) pathway. To increase pulmonary vasodilatation dependant on NO, a recent therapeutic strategy has targeted type 5 phosphodiesterase which degrades cGMP. Sildenafil or tadalafil, type 5 phosphodiesterase inhibitors, have proven their efficacy in patients with PAH [155]. Vasoactive intestinal peptide (VIP) is a neurotransmitter that has systemic and pulmonary vasodilator properties. It also inhibits smooth cell proliferation and decreases platelet aggregation and acts via the activation of the cAMP and cGMP systems [156]. Low plasmatic concentrations of VIP have been measured in pulmonary arteries of patients with PAH.

Endothelin-1 (ET-1) is an endothelially-derived peptide that has two receptor subtypes, designated as endothelin A (ETRA) and endothelin B (ETB), located on smooth muscle cells of pulmonary arteries. By ligating the ETRA, ET-1 intracellular calcium concentrations increase and activates the protein kinase C pathway [157]. ET-1 is a potent pulmonary vasoconstrictor and stimulates mitosis of arterial smooth muscle cells, thus contributing to pulmonary vascular remodeling. Pulmonary and plasma levels of ET-1 are elevated in human PAH and in experimental animal models of PAH [158]. The therapeutic efficacy of endothelin receptor antagonists (Ambrisentan, Bosentan) has been demonstrated in clinical trials in the pathophysiology of $\mathrm{PAH}$.

In hypoxic models of PAH, hypoxia inhibits one or several voltage dependant potassium channels of the pulmonary arterial smooth muscle cells. This leads to membrane depolarization and opening of voltage dependant calcium channels with a subsequent increase of the intracellular calcium concentration and cellular contraction. Certain potassium channels are under expressed in pulmonary artery smooth muscle cells of patients with PAH $[159,160]$. It is still unknown whether abnormalities of the potassium channels are acquired or genetic. However, it has been demonstrated that anorexigens, such as dexfenfluramine and aminorex, directly inhibit certain potassium channel subtypes [161].
Certain medications such as dichloroacetate and sildenafil increase the expression and function of potassium channels.

In $\mathrm{PAH}$, plasmatic concentrations of serotonin (5-hydroxytryptamine, 5-HT) are elevated [150]. An association between anorexigens and serotonin was established in the 1960s. Aminorex and fenfluramin both increase plasmatic levels of serotonin. The variability of the expression and activity of the transporter of 5-HT (5-HTT) contributes to pulmonary vascular remodeling in human and experimental models of PAH [162]. Some studies have shown that the serotonin selective reuptake inhibitor fluoxetin prevents the development of PAH in mice [163]. Some 5-HT receptor subtypes may also be implicated in the development of hypoxia induced PAH [164].

Rho proteins regulate fundamental cellular functions such as contraction, migration, proliferation and apoptosis. Several studies have implicated Rho protein A and Rho kinases in the vasoconstriction and vascular remodeling of PAH $[165,166]$. RhoA and Rho kinase activities are increased in idiopathic $\mathrm{PAH}$, in association with enhanced RhoA serotonylation. Direct involvement of the 5-HTT/RhoA/Rho kinase signaling pathway in 5-HTTmediated pulmonary artery-smooth muscle cell (PASMC) proliferation and platelet activation during $\mathrm{PH}$ progression identify RhoA/Rho kinase signaling as a promising target for new treatments against $\mathrm{PH}$ [167].

Hypoxia inducible factor-1 (HIF-1) is a transcription factor that principally regulates cellular adaptation to hypoxia but also regulates several genes implicated in angiogenesis, erythropoiesis, cellular metabolism and survival [168]. In experimental mice heterozygote for the gene coding for HIF-1 alpha, hypoxia induced right ventricular hypertrophy, right ventricular pressure and medial thickening of pulmonary arterioles are reduced [169]. In immunohistological analysis of human plexiform lesions of patients with severe $\mathrm{PAH}$, there was an overexpression of HIF-1 alpha in proliferating endothelial cells [170].

In conclusion, the pathophysiology of $\mathrm{PAH}$ is heterogeneous and multifactorial. The genetic mutations found in familial PAH and in a proportion of sporadic PAH are neither necessary nor sufficient for the development of PAH. Therefore, the current hypothesis is that of a genetic predisposition for PAH followed by a superimposed environmental factor (infection, inflammation, autoimmunity). Our understanding of the underlying pathophysiological mechanisms of $\mathrm{PAH}$ has lead to the development of new treatments such as prostacyclin analogues, endothelin receptor antagonists and type 5 phosphodiesterase inhibitors. However, future progress is still necessary in order to discover new pathophysiological pathways and to develop new therapeutic strategies in PAH. 


\section{Histopathology: vascular changes}

Vascular remodelling in pulmonary arterial and venous hypertension typically involves the small pulmonary vessels. Muscular arteries of less than $500 \mu \mathrm{m}$ display a thickening within the intimal, medial and adventitial compartment. When involved, pulmonary veins of the interlobular septa and smallest preseptal venules show fibrous obliteration and / or muscularization. Even the smallest vascular level may be involved: patients with pulmonary venous hypertension frequently present focal proliferation of alveolar capillaries. The different histological pattern is presented here below.

\section{Arterial lesions}

\section{Isolated medial hypertrophy}

This abnormality of the vessel wall can be observed in all subgroups of PAH and may even be encountered in other forms of $\mathrm{PH}$, e.g. in mitral valve stenosis. The lesion corresponds to a smooth muscle cell proliferation and / or recruitment within the tunica media; the histological criterion of hypertrophy / hyperplasia is fulfilled, when the diameter of a single medial layer, delimited by its internal and external elastic lamina, exceeds 10 per cent of the arteries cross-sectional diameter (Figure 2A). Isolated hypertrophy of the medial layer may be considered as an early and even reversible event as it has been shown in PH due to hypoxia in high altitude [171]. However, medial hypertrophy is usually associated with other PAH-lesions.

\section{Concentric and eccentric non-laminar intimal fibrosis}

Fibrotic lesions of the intimal layer are frequent in PAHdiseased lungs. The intima may be thickened by proliferation and recruitment of fibroblasts, myofibroblasts and other connective tissue cells, and consequently by the interstitial deposition of collagen (Figure 2B, C). In a purely descriptive approach, this thickening may be uniform and concentric, or focally predominating and eccentric. However, the eccentric intimal thickening is frequently observed in cases with thrombotic events and could represent residues of wall-adherent, organized thrombi. Thrombotic lesions, or so called in situ thrombosis, are a frequent pattern in different PAH-subgroups: organization and recanalization of totally occluding thrombotic material may lead to bizarre, fibrotic multi-channel lesions (so called "colander-like" lesions) which can be easily confounded with proliferative complex lesions (see below) (Figure 2D). Frequently, adventitial fibrosis is associated to intimal modifications (Figure 2A, B).

\section{Concentric laminar intimal fibrosis}

This morphologically conspicuous phenotype of intimal fibrosis is also known as "onion-skin" or "onion-bulb" lesion. Numerous concentrically arranged fibrotic layers occlude the arterial lumen of small (diameter: 100$200 \mu \mathrm{m})$ arteries (Figure 2E). The scary, cell-lacking morphology of this lesion is frequently found in patients suffering from idiopathic $\mathrm{PAH}$ and $\mathrm{PAH}$ associated to CTD [172]. Nevertheless, immunohistochemical analysis reveals fibroblasts, myofibroblasts and smooth muscle cells.

\section{Complex lesions}

The pathological classification of the World Symposium meetings in Venice and in Dana Point comprises three patterns, plexiform lesion, dilation lesion and arteritis. The plexiform lesion probably represents the most illustrious form of vascular lesions in PAH and affects various vascular compartments: focal intimal thickening of small pulmonary arteries, preferably beyond branching points and exuberant endothelial cell proliferation, leading to the formation of capillary-like, sinusoidal channels on a smooth muscle cell and collagen-rich matrix within the native arterial lumen and resulting in obstruction $[173,174]$. This glomeruloid-like arterial zone feeds into dilated, vein-like congestive vessels, which are perceivable at low magnification (Figure 2F). The latter veinlike vessels are also known as dilation lesions and may predominate the histological pattern (Figure 2G). Classical arteritis with transmural inflammation and fibrinoid necrosis, as first described by Heath and Edwards for $\mathrm{PAH}$ associated to congenital cardiac disease (Eisenmenger), is not a regular finding in PAH [175]. Nevertheless, perivascular inflammatory infiltrates of diseased pulmonary arteries in PAH-patients, consisting mainly of T- and B-lymphocytes, dendritic cells, mastcells and macrophages can be regularly found [141,148,176] (Figure 2H). It has not been elucidated until now, whether this inflammatory pattern is of pathogenetic importance, or if it represents a pure epiphenomenon within disease evolution. The reported evidence of proinflammatory mediators, so called chemokines, released by altered endothelial cells of PAH-lungs strongly indicates a self-supporting and selfamplifying process $[145,177]$.

\section{Venous and venular lesions (Pulmonary veno-occlusive disease and pulmonary hemangiomatosis)}

A clear-cut differentiation between pre-and post-capillary pulmonary vascular lesions is sometimes difficult to make: lesions frequently concern veins and arteries in lungs of patients with PVOD, and vice-versa veins may be strongly involved in some subgroups of PAH. This is not contradictory because the clinical approach to 'difficult-to-treat' PAH-groups may be similar to clinical management of PVOD and PVOD-patients are frequently treated - under great precaution - with pulmonary arterial dilators, e.g. prostanoids. Recent reports, for example, indicate that 


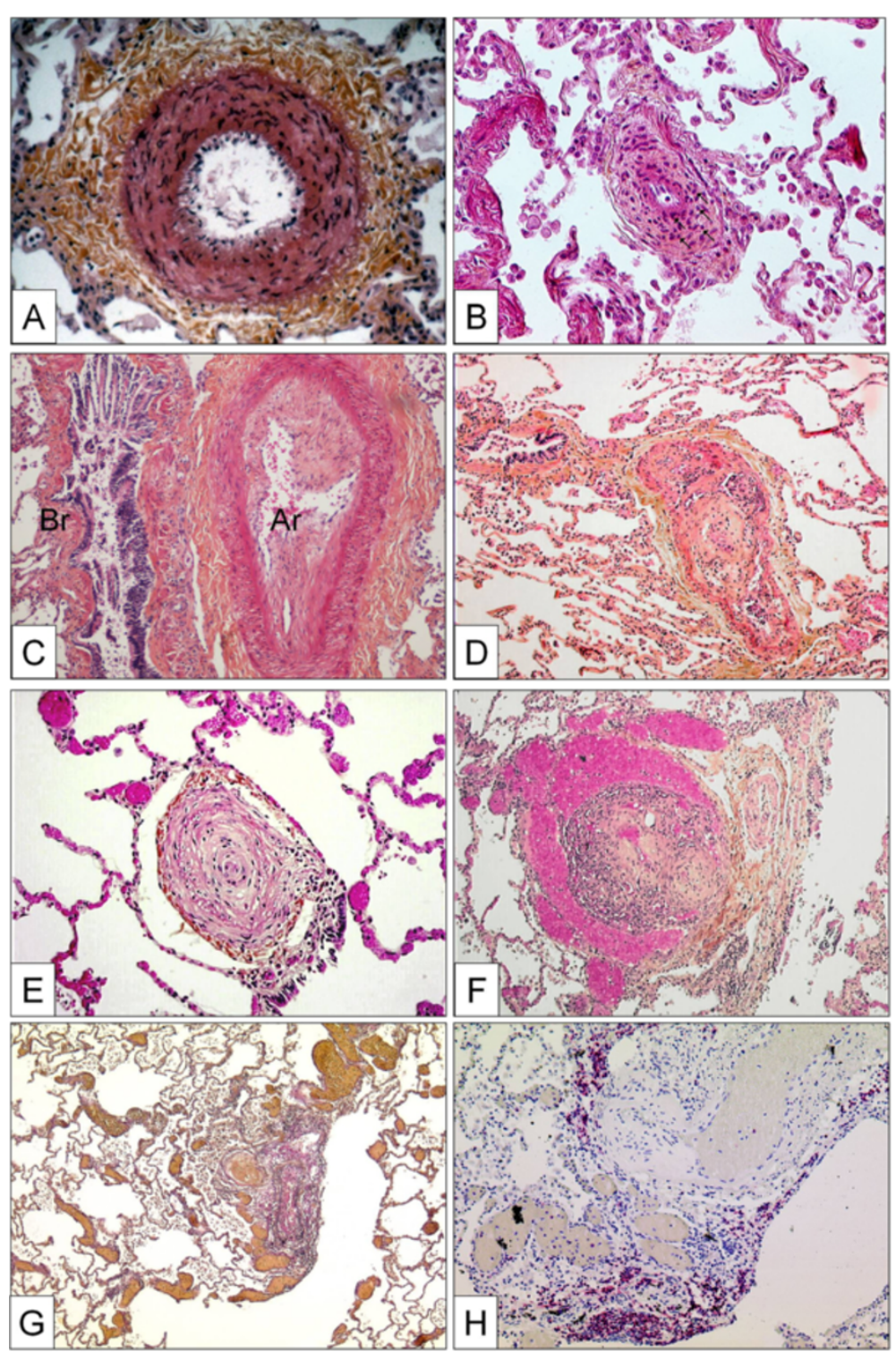

Figure 2 Pulmonary arteries of the muscular type displaying obstructive arteriopathy in lungs of patients with PAH. A Medial hypertrophy with smooth muscle cell proliferation and pronounced adventitial fibrosis. Magnification x200, Weigert-hematoxylin-phloxine-saffron staining (WHPS). B Concentric non-laminar intimal fibrosis comprising numerous myofibroblasts (arrows). C Eccentric intimal fibrosis corresponding to organized thrombotic material. Br: bronchus, Ar: pulmonary artery. Magnification x 100, HES staining. D Thrombotic lesion, so called "colander-like lesion", with partial recanalization by microvessels. Note the similarity to plexiform lesions (F). Magnification x100, HES. E Concentric laminar intimal fibrosis, so called "onion-skin lesion“. Magnification $\times 200$, HES. F Plexiform lesion with proliferation of small sinusoidlike vessels on a fibrotic matrix. Note surrounding dilated vessels. Magnification x100, HES. G Multiple dilation lesions being the sentinel of the centrally located plexiform lesion. Magnification $\times 40$, Elastica-van-Gieson staining (EvG). $\mathbf{H}$ The same plexiform lesion after immunohistochemical staining with anti-CD3, a T-lymphocytic marker. Note the perivascular distribution of the inflammatory infiltrate. Magnification x100.

CTD associated PAH, classically being considered as precapillary PH, simultaneously displays a PVOD-like pattern in histology $[178,179]$. Like in PVOD, the observed postcapillary lesions concern septal veins and pre-septal venules and usually consist of a loose and pauci-cellular and cushion-like intimal fibrosis that may totally occlude the lumen. A muscularization of both, septal veins and pre-septal venules may be observed (Figure 3A, B).
Importantly, occult pulmonary hemorrhage regularly occurs in patients displaying PVOD. This particularity, which is certainly due to the post-capillary bloc, is of diagnostic importance, as bronchio-alveolar lavage can reveal an occult hemorrhage. The degree of hemorrhage can be evaluated semi-quantitatively and qualitatively using the Golde Score, which takes number and Perls-PrussianBlue staining-degree of intra-alveolar siderophages into 
consideration (Figure 3C) [180]. Pulmonary capillary hemangiomatosis has been historically described as an aggressive capillary proliferation with patchy distribution within the pulmonary parenchyma: alveolar septa are thickened by 3 to 4 capillary layers, and infiltration of venous and bronchiolar structures with secondary occlusion may be present (Figure 3D). It is thought, that a clinically relevant post-capillary bloc is owed to this angiomatoid expansion. Occult hemorrhage or hemosiderosis, therefore, is frequently found [181]. However, Lantuejoul and co-workers have shown in a remarkable retrospective histological analysis, that capillary hemangiomatosispattern is virtually always present in PVOD, and veinremodelling is constantly observed in case with a primary diagnosis of $\mathrm{PCH}$ [54]. The authors suggest the possibility, that PVOD and PCH might be the same disease, with a vein- or a capillary-predominating pattern. We fully support this view, and in our experience from the French National PH Reference Center, no clinical distinction is made between both conditions.

\section{Clinical description}

\section{Symptoms and clinical signs of $\mathrm{PH}$}

There is no pathognomonic clinical sign of PH. Clinical presentation is related either to right heart failure or to associated diseases. Persistant dyspnea on exertion is the most frequent symptom; and it is present in almost patients even in the presence of mild hemodynamic abnormalities $[1,182]$. Dyspnea usually starts insiduously and is often neglected by patients which explain the delay of around two years in establishing the diagnosis of $\mathrm{PH}$. The New York Heart Association (NYHA) provides a classification system for the clinicial evaluation of dyspnoea. Four categories are proposed to classify patients in functional classes (FC) based on how much they are limited during physical activity; the limitations/symptoms are in regard to normal breathing (Table 3).

However, at time of diagnosis, $70 \%$ of patients are in NYHA FC III or IV. Chest pain, light-headedness and syncope may occur, particularly during physical efforts and are major signs of disease severity. Palpitations are frequent during physical efforts and may reveal true cardiac arrhythmias. Other symptoms of PAH include fatigue and weakness. Hemoptysis may complicate $\mathrm{PAH}$ and could be life-threatening, justifying embolization of dilated bronchial arteries. Hoarseness of the voice may occasionally be noted and is due to compression of the left laryngeal nerve by the dilated pulmonary artery (Ortner's syndrome).

Signs of right heart failure may be observed in the most severe patients, including venous jugular distension, hepato-jugular reflux, hepatomegaly and hepatalgia. Lower limb edema, ascitis and generalized edema underscore the severity of right heart failure. Cardiac auscultation shows usually a prominent pulmonary component of S2, a systolic murmur of tricuspid regurgitation and more rarely a diastolic murmur of pulmonary regurgitation. Pulmonary auscultation is usually normal and contrasts with the importance of dyspnea. History and clinical examination should also screen for manifestations of extra thoracic diseases, particularly Raynaud's syndrome which can be found in PAH associated with CTD and particularly in systemic sclerosis.

\section{Diagnostic methods}

The diagnostic process of PAH requires a series of investigations that are intended to make the diagnosis, to clarify the clinical class of $\mathrm{PH}$ and the underlying type of $\mathrm{PAH}$ and to evaluate the functional and hemodynamic impairment [183]. The detection of PH requires investigations including electrocardiogram, chest radiograph and trans-thoracic echocardiogram. Other conditions which can induce $\mathrm{PH}$ will be identified by tests such as pulmonary function tests, arterial blood gases, ventilation and perfusion lung scan, high resolution computed tomography (HR-CT) of the chest and pulmonary angiography. Additional investigations are required for evaluation of PAH severity including exercise testing and hemodynamics. Additional imaging may clarify underlying lung abnormalities. Finally, right heart catheterisation confirms the definite diagnosis.

\section{Electrocardiogram (ECG)}

The ECG may provide suggestive or supportive evidence of $\mathrm{PH}$ by demonstrating right ventricular hypertrophy and strain, and right atrial dilation. Right ventricular hypertrophy and right axis deviation are present in respectively $87 \%$ and $79 \%$ of patients with idiopathic $\mathrm{PAH}$ [105]. Unfortunately, the ECG has low sensitivity and specificity as a screening tool for detecting $\mathrm{PH}$.

\section{Chest radiography}

In $90 \%$ of idiopathic PAH patients, chest radiography is abnormal at the time of diagnosis [105]. Findings include central pulmonary arterial dilatation which contrasts with loss of the peripheral blood vessels. Right atrial and ventricular enlargement may be seen in more advanced cases. Chest radiography may help to identify associated moderate-to-severe lung disease or pulmonary venous hypertension due to left heart abnormalities.

\section{Pulmonary function test and arterial blood gases}

Pulmonary function tests (PFT) will help to assess underlying lung abnormalities. Forced expiratory volume in one second (FEV1) and total lung capacity (TLC) in idiopathic $\mathrm{PAH}$ are usually normal or slightly abnormal. Low diffusing capacity of the lung for carbon monoxide (DLCO) has been reported in PAH patients, but is more pronounced in PVOD patients with often severe reductions under $50 \%$ of 

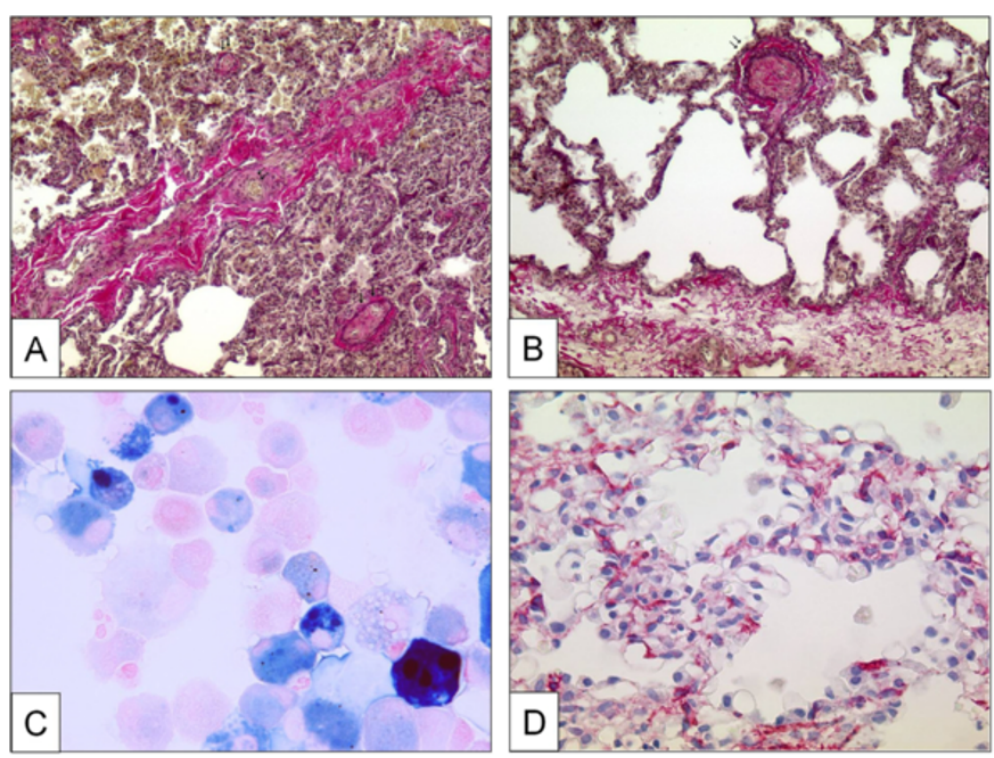

Figure 3 Pulmonary veins with obstructive venopathy in lungs of patients with PVOD and a case of pulmonary capillary

hemangiomatosis. A Longitudinally dissected septal vein with asymmetric intimal and partially occlusive fibrosis. Note the intra-alveolar hemorrhage due to the post-capillary block on the upper half of the photograph. Magnification $\times 100$, EvG. B Pre-septal venule with occlusive intimal fibrosis. Magnification $\times 100$, EvG. C Bronchio-alveolar lavage in a PVOD-patient. Perls-Prussian-Blue staining. Note the siderophages displaying gradually different color-shades (see text). Magnification $\times 400$. D Excessively proliferating alveolar capillaries in a patient with pulmonary capillary hemangiomatosis. Note protrusion of ectatic lumina into the alveoli. Magnification × 200, anti-CD31 staining.

the predicted value $[56,184]$. Results of arterial blood gases usually show mild hypoxemia and hypocapnia. Severe hypoxemia may be a parameter of underlying PVOD or chronic lung disease.

\section{Exercise testing}

The normal physiologic response of the pulmonary vasculature to exercise consists of distension of pulmonary arteries and arterioles as well as recruitment of previously unused vascular bed. Thus, in health, pulmonary artery pressure rises minimally in response to increased blood flow and pulmonary vascular resistance decreases because of the remodeled vasculature. These mechanisms are impaired in the course of PH. Cardiopulmonary exercise testing (CPET) has been shown to be useful in assessing the severity and prognosis of $\mathrm{PAH}$ [15,185]. Several mechanisms are associated: (1) failure to perfuse the ventilated lung, leading to an increase of physiologic dead space and ventilatory requirement; (2) failure to increase cardiac output appropriately in response to exercise, causing an early lactic acidosis, thereby increasing acid ventilatory drive; and (3) exercise-induced hypoxemia increasing the hypoxic ventilatory drive. The ventilatory expired gas abnormalities precipitated by $\mathrm{PH}$ are multifactorial and associated with disease severity. CPET assesses and measure the ventilation-perfusion mismatch (i.e. acceptable ventilation/diminished perfusion), reflected by an elevated VD/VT or VE/VCO2 ratio or slope and diminished partial pressure of end-tidal carbon dioxide (PETCO2), and the decreased peak VO2 and VO2 at the ventilatory threshold (VT). Peak VO2, VE/VCO2 ratio or slope or PETCO2, measure during CPET, all demonstrated independent and strong prognostic value as univariate markers [186].

\section{Transthoracic doppler-echocardiography (TTE)}

TTE is a non-invasive screening test for patients with suspected PH. TTE estimates pulmonary artery systolic pressure (sPAP) and may provide additional information about the cause and consequences of PH. The estimation of PAP is based on the peak velocity of the jet of tricuspid regurgitation. The simplified Bernoulli equation describes the relationship of tricuspid regurgitation velocity and the peak pressure gradient of tricuspid regurgitation $=4 \mathrm{x}$ (tricuspid regurgitation velocity). Estimation of PA systolic pressure require to take into account right atrial pressure (PA systolic pressure $=$ tricuspid regurgitation pressure gradient + estimated right atrial pressure). Right atrial pressure cannot be measured and is estimated based on the diameter and respiratory variation of the inferior vena cava [15]. An alternative approach to echocardiographic diagnosis of $\mathrm{PH}$ is based on the comparison of tricuspid regurgitation velocity with values reported in a healthy population. Ideally, the influence of age, sex and body mass should be taken into consideration [187]. This method avoids cumulative error but is less directly linked to the accepted hemodynamic definition of $\mathrm{PH}$ based on mPAP [15]. 
Other echocardiographic variables that might raise or reinforce suspicion of $\mathrm{PH}$ independently of tricuspid regurgitation velocity should always be considered. They include an increased velocity of pulmonary valve regurgitation and a short acceleration time of RV ejection into the PA. Increased dimensions of right heart chambers, abnormal shape and function of the interventricular septum, increased RV wall thickness, pericardial effusion and dilated main PA are also suggestive of $\mathrm{PH}$, but these signs are considered to be related to the hemodynamic severity [15].

Besides identification of PH, TTE also allows a differential diagnosis of the possible causes of pulmonary hypertension. TTE can recognize left heart valvular diseases and myocardial diseases responsible for postcapillary $\mathrm{PH}$, and congenital heart diseases with systemic-to-pulmonary shunts. The venous injection of agitated saline can help to identify patent foramen ovale or small sinus venosus type atrial septal defects. Transesophageal echocardiography is rarely required in the setting of $\mathrm{PH}$.

\section{Ventilation/perfusion lung scan}

Ventilation/perfusion lung scan should be systematically assessed to screen for CTEPH. Indeed, $\mathrm{V} / \mathrm{Q}$ lung scan is the method of choice to detect CTEPH [188] and normal V/Q scan can eliminate CTEPH.

\section{High resolution computed tomography of the chest}

High resolution computed tomography of the chest (HRCT) supplies detailed information about underlying lung parenchyma disease, such as pulmonary emphysema or interstitial lung disease. A number of various pathologic features may be detected on chest HRCT including pericardial effusions and pulmonary artery enlargement, defined by the ratio of the diameter of main pulmonary artery to that of the thoracic aorta $>1$. In the setting of CTEPH, contrast HRCT of the pulmonary arteries may show changes like complete vessel obstruction, vessel cut-offs, intimal irregularities, incorporated thrombus formations as well as bands and webs [189]. Furthermore, collaterals from bronchial arteries can be identified with this technique. Proximal pulmonary obstruction is displaying about significant and accessible organized fibrous tissue in segmental or subsegmental arteries. If no proximal obstruction or obliteration is noted; lesions are considered to be distal, non-accessible to surgery intervention. In some cases, pulmonary angiography is necessary to differentiate between proximal or distal obstructions. Chest HRCT may also suggest PVOD in the presence of adenopathy mediastinal, ground glass opacities and septal lines [53].

\section{Pulmonary angiography}

In CTEPH, pulmonary angiography may be helpful to determinate surgically accessible form. Typical angiographic findings in CTEPH are complete obstruction, band and webs as well as intimal irregularities [74]. Pulmonary angiography may be also helpful in the setting of fibrosing mediastinitis.

\section{Cardiac magnetic resonance imaging}

Cardiac magnetic resonance imaging (MRI) allows non invasive evaluation of right ventricular size, morphology and shape. It provides information on right ventricular function and allows non-invasive assessment of blood flow including cardiac output, stroke volume, distensibility of pulmonary artery and right ventricular mass [190,191]. Decreased stroke volume, an increased right ventricular right ventricular end-diastolic volume and a decreased measured at baseline are associated with poor prognosis of disease [192,193]. In addition, it has been demonstrated that deterioration of these parameters at one-year follow-up were also predictors of mortality [193]. Thus cardiac MRI could represent a non-invasive tool to evaluate severity of PAH patients at baseline and during follow-up. Further studies are needed to evaluate the precise place of cardiac MRI in the management of PAH patients.

\section{Abdominal ultrasound scan}

Abdominal ultrasound should be performed in all patients if $\mathrm{PH}$ is suspected to exclude portal hypertension or liver disease. When portal hypertension is suspected, the diagnosis can be confirmed during RHC by measurement of an increased gradient between the free and occluded hepatic vein pressure [194].

\section{Blood tests}

Serological tests for HIV, hepatitis B or C serology should be performed to screen for associated diseases. The thyroid hormone measurement may reveal either hyperthyroid dysfunction or autoimmune thyroiditis, frequently encountered in PAH.

\section{Right heart catheterization}

Invasive hemodynamic assessment with right heart catheterization is requested to confirm the diagnosis of PH showing a resting $\mathrm{mPAP}$ of $\geq 25 \mathrm{mmHg}$ and a normal PCWP [2]. This value has been used for selecting patients in all RCTs and registries of PAH, however normal mPAP at rest is around of $14 \mathrm{mmHg}$, with an upper limit of normal of $20 \mathrm{~mm} \mathrm{Hg}$. The significance of a mean PAP between 21 and $24 \mathrm{mmHg}$ is currently unclear. No definition of $\mathrm{PH}$ on exercise was currently adopted, because of the large variability of mPAP on exercise in healthy individuals. 
The assessment of PCWP may allow the distinction between precapillary (normal PCWP $\leq 15 \mathrm{mmHg}$ ) and postcapillary $\mathrm{PH}$ (PCWP $>15 \mathrm{~mm} \mathrm{Hg}$ ). In post-capillary $\mathrm{PH}$, the last guidelines from the 4th World Symposium (Dana Point) proposed a dichotomy between "passive" and "reactive" (out-of-proportion) post-capillary $\mathrm{PH}$ based on transpulmonary pressure gradient (mPAPPCWP, respectively $\leq$ or $>12 \mathrm{~mm} \mathrm{Hg}$ ). Indeed, there is no clear consensus on this definition and the future recommendations arising from the last World Symposium on PH (Nice, 2013) should propose new definition to define these two entities.

Measurement values obtained by $\mathrm{RHC}$ are PAP (diastolic, mean and systolic), right atrial pressure (RAP), PCWP, right ventricular pressure and cardiac output (CO) preferably by the thermodilution method. In contrast to the thermodilution method, the Fick method is mandatory in patients with suspected CHD. In experienced centres, RHC procedures have low morbidity and mortality rates [195]. Elevated mean right atrial pressure reduced $\mathrm{CO}$ and mixed venous oxygen saturation (SVO2) are related to the prognosis of PAH patients.

\section{Assessment of disease severity}

NYHA functional class at baseline or after initiation of epoprostenol treatment, signs of right heart failure, 6-MWD, peak VO2, echocardiographic parameters, hemodynamic parameters and biological tests (hyperuricemia, brain natriuretic peptide, troponin) predict prognosis in idiopathic PAH when assessed at baseline.

Patients presenting PVOD or PAH associated with CTD (frequently associated with venous involvement) have a worse prognosis than patients with idiopathic $\mathrm{PAH}$ [53]. Patients with PAH associated with congenital systemic to pulmonary shunts have a more slowly progressive course than idiopathic PAH patients. Few data are available in other conditions such as HIV infection or portal hypertension. In these circumstances, underlying diseases may contribute to the overall outcome. In clinical practice, the prognostic value of a single variable in the individual patient may be less significant than the value of multiple concordant variables.

A score has been proposed (REVEAL Registry Risk Score) to evaluate severity of newly diagnosed PAH patients [196]. This score was based on several parameters including subgroups of $\mathrm{PAH}$, renal insufficiency, age $>60$ years, NYHA FC, systolic blood pressure, heart rate, 6-MWD, BNP, pericardial effusions, DLCO, RAP and PVR [196].

\section{Management of PAH}

\section{General measures}

Physical activities

Peripheral vasodilatation or increased cardiac demand will put $\mathrm{PAH}$ patient at risk of acute cardiac failure and syncope. Thus, we traditionally advise against extreme physical activity. Patients are taught to stay active while adapting effort according to their symptoms. Nevertheless, the appropriate level of physical activity is difficult to define. To date, only few studies have evaluated to effect of cardio-respiratory rehabilitation in PAH. One of this program involved three weeks of inpatient rehabilitation followed by three month training at home with phone call supervision. No modification on cardiac hemodynamic was observed on echocardiography but 6-MWD and quality of life were improved. As proposed in ERS/ESC guidelines, more data are required before appropriate recommendations can be made [15].

\section{Altitude and hypoxia}

As hypoxic vasoconstriction may be an aggravating factor in PAH, stays at altitude above 1500-2000 meters without supplemented oxygen and air flight in unpressurized cabin should be avoided [15]. Chronic hypoxia ( $\mathrm{PaO} 2<60 \mathrm{mmHg}$ ) warrants oxygen therapy for symptoms and to avoid PAH deterioration.

\section{Pregnancy and contraception}

The hemodynamic and hormonal modifications occurring during pregnancy and peripartum period can lead to severe, and sometimes fatal, right heart failure [197,198]. Pregnancy is considered to be associated with high rate of mortality (30-50\%) in PAH patients [15]. Thus, pregnancy is contraindicated in women affected by PAH. Consequently, contraception is strongly recommended in PAH women of childbearing age $[197,198]$. Combined estrogen-progestin oral contraceptive is theoretically contraindicated because their pro-thrombotic activity. Therefore, mechanical contraception (intra-uterine device for example) or surgical sterilization should be proposed. Nethertheless, pregnancy should be managed with specific $\mathrm{PAH}$ therapies and planned elective delivery in expert centres [15].

\section{Anaesthesia and surgery}

Hypotension induced by anaesthetic drugs, and hemodynamic insults following surgical and anaesthetic interventions are generally poorly tolerated by $\mathrm{PAH}$ patients, with a high procedural morbidity and mortality. Consequently, it is recommended in general that $\mathrm{PAH}$ patients avoid unnecessary procedures. When required, these should be highly planned with the multidisciplinary team, either within, or in close liaison with, the expert centers, in order to coordinate surgical and medical interventions [199].

\section{Proscribed drugs}

Vasoconstrictors used in cold medication to relieve nasal congestion should be avoided in PAH patients. Beta- 
blockers have been shown to be deleterious to PAH patients because they prevent the important adaptive physiologic response that allows preservation of adequate cardiac output. To discontinue such drugs in a patient with PAH may lead, by itself, to important clinical and hemodynamic improvement [200].

\section{Non specific drugs Diuretics}

Diuretics are one of the most important treatments in the setting of PAH because right heart failure leads to fluid retention, hepatic congestion, ascites and peripheral edema. Right ventricular overload is part of clinical symptoms and has been associated with a poor prognosis in PAH [201]. Diuretics and salt-free diet relieve hypervolemia and associated symptoms. Whether this strategy improves prognosis is unknown. Dose adjustment of diuretics is needed, based on clinical and hemodynamic findings. Renal function and blood chemistry should be monitored to avoid renal failure or dyskalemia [192].

\section{Oral anticoagulation}

Pathology specimens from PAH patients may show in situ thrombosis and thrombi recanalisation. Only few studies support anticoagulation treatment in PAH (mostly retrospective or not randomized) [202,203]. Current recommendations propose oral anticoagulation aiming for targeting an International Normalized Ratio (INR) between 1.5 and 2.5. Although the somewhat sparse evidence base is derived exclusively from idiopathic, heritable and PAH due to anorexigens, anticoagulation has been generalised to all patient groups, given the absence of contraindication. Anticoagulation is usually not recommended in porto-pulmonary hypertension because of the risk of esophageal variceal haemorrhage. In patients with systemic sclerosis, oral anticoagulation can be difficult to manage because of their high risk of bleeding, especially from the gastrointestinal tract. Variceal ligation is a preventive option in these cases. Long-term oral anticoagulation is essential in CTEPH with an INR which is recommended to be between 2 and 3 .

\section{Digitalis}

Digoxin has been suggested as part of PAH therapy in the past because it produces an acute increase in cardiac output [204], although its efficacy is unknown in PAH. Therefore it is usually proposed in PAH associated with atrial tachyarrhythmias [192].

\section{Calcium channel blockers}

Calcium channel blockers (CCB) are indicated in patients with a positive vasodilatation challenge test after inhaled NO. CCB are vasodilators and were initially introduced in the 1980's as part of PAH therapy to counteract vasoconstriction that has traditionally been assumed to be a preponderant mechanism in PAH. In the 1990's, Rich and colleagues showed in an open prospective study that high dose of calcium channel blockers (nifedipine 90 to $240 \mathrm{mg}$ /day or diltiazem 360 to $900 \mathrm{mg} /$ day) significantly improve prognosis in patients with an acute vasodilation response [203]. Sitbon et al. showed that only $12.6 \%$ out of the patients could be treated by CCB according to criteria's establish by Rich and coworkers [203]. Moreover, only half of them maintained actual long-term benefit defined as NYHA FC I or II at one year without the need for additional treatment [205]. In this study, a decrease in mean PAP $>10 \mathrm{mmHg}$ to reach a value $<40 \mathrm{mmHg}$, with a stable or increased cardiac output, during acute vasodilator test was predictive of long-term response to CCB. Contrarily, CCB must be avoided in the absence of acute vasoreactivity because of the risk of significantly reduced cardiac output and systemic blood pressure [205]. The choice of CCB is based upon the patient's heart rate; nifedipine and amlodipine were preferred in the presence of relative bradycardia and diltiazem in the presence of tachycardia. Doses of CCB used in this setting are relatively high, $120-240 \mathrm{mg}$ de nifedipine, $240-$ $270 \mathrm{mg}$ for diltiazem, and up to $20 \mathrm{mg}$ for amlodipine [15]. If the patient does not show a correct response (NYHA FC I or II with marked hemodynamic improvement), additional PAH specific therapy should be added. Of note, CCB is contraindicated in PVOD because of the high-risk of life threatening pulmonary edema, even in the presence of acute vasodilator response that can be observed in the same proportion as in idiopathic PAH [53].

\section{PAH-specific therapies}

Better understanding in pathophysiological mechanisms of $\mathrm{PH}$ over the past quarter of a century has led to the development of medical therapeutics, even though no cure for pulmonary arterial hypertension exists. Several specific therapeutic agents were developed for the medical management of PAH including prostanoids, endothelin receptor antagonists and phosphodiesterase type 5 inhibitors. Furthermore, emerging treatments such as tyrosine kinase inhibitors, soluble guanylate cyclase activators (riociguat) and prostacyclin receptor agonists (selexipag) are currently being evaluated in $\mathrm{PAH}$.

\section{Prostanoids}

Endothelium-derived prostaglandin I2 (PGI2), or prostacyclin, is an arachidonic acid produced by endothelial cells. Prostacyclin is a powerful systemic and pulmonary vasodilator and an inhibitor of platelet aggregation through the increase in intracellular cyclic adenosine monophosphate (cAMP) [206,207]. Moreover, prostacyclin plays an important role in antiproliferative, antithrombotic, antimitogenic 
and immunomodulatory activity [208]. Prostanoids are a family of prostacyclin analogues available in intravenous, subcutaneous, or inhaled form.

Epoprostenol In the 1980s, intravenous epoprostenol was the first prostanoid evaluated in PAH [209]. As the half-life of epoprostenol is $<5$ minutes, it requires an indwelling central venous catheter which is connected to an infusion pump for continuous intravenous administration. Treatment with epoprostenol is complex, uncomfortable and expensive and cannot be considered as an ideal treatment despite its evident clinical benefit. Common side effects associated with treatment include headache, flushing, jaw pain and gastrointestinal disturbance $[201,210]$. The efficacy of continuous i.v. administration of epoprostenol has been tested in three unblinded RCTs in idiopathic PAH $[207,211]$ and PAH associated with systemic sclerosis [212].

Barst and colleagues [183] showed improvement in exercise capacity with an increase in 6-MWD of 47meters after 12 months of epoprostenol treatment in 81 patients with idiopathic PAH. Moreover, a significant improvement of survival was observed (no death at three months of treatment in the group with epoprostenol against 8 deaths in the group receiving conventional treatment including diuretics and anticoagulants [213]. Long-term persistence of efficacy has also been shown [201,214] in idiopathic PAH, as well as in other associated PAH $[215,216]$ and in non operable CTEPH [217]. Long term effectiveness has never been evaluated prospectively but retrospective analysis comparing patients treated by intravenous epoprostenol with data from patients treated with conventional therapy find meaningful clinical benefit for patients in NYHA FC III or IV [201,214,218,219]. Functional class, hemodynamic parameters and long term survival were all improved in the group treated with i.v. epoprostenol.

Epoprostenol had initially been proposed as a bridging therapy for lung transplantation but it is currently regarded as the treatment of choice for patients in NYHA FC IV. If treatment with epoprostenol is necessary, it will be started at low dose of $2-4 \mathrm{ng} / \mathrm{kg} / \mathrm{min}$ and is gradually increased to $10-16 \mathrm{ng} / \mathrm{kg} / \mathrm{min}$ according to side effects [201]. Treatment interruption secondary to pump dysfunction or the rupture of the catheter, although rare, can induce serious adverse events [201]. Because of its route of administration, central venous catheter bloodstream infections can occur, and should be systematic searched in the context of unexplained clinical deterioration.

Treprostinil Due to complications related to the central venous catheter used for the i.v. administration of epoprostenol, other prostacyclin agonists have been developed. Treprostinil is a prostacyclin analogue which benefits from a longer half-life of 58-83 minutes by subcutaneous administration [220]. It is delivered by a minipump similar to those used for insulin [221]. A multicenter randomized trial evaluated subcutaneous administrated treprostinil versus placebo over three months in patients in NYHA functional class II-IV suffering from idiopathic PAH, PAH related to $\mathrm{CHD}$ with a shunt or $\mathrm{PAH}$ associated with CTD [221]. Patients treated with treprostinil increased 6-MWD and had benefits like quality of life, pulmonary hemodynamics and improvement of clinical symptoms. Unfortunately, local side-effects such as pain and inflammation at the injection site are present in the majority of patients treated with treprostinil which often lead to limitation of increasing dose or treatment cessation. Intravenous treprostinil is only licensed for the use in the USA and provides the advantage of less frequent need for drug reservoir replacement [220]. Inhaled treprostinil was examined in a placebo-controlled TRIUMPH-1 study [222], but results of this formulation were not convincing and this product is not yet licensed outside the USA.

Inhaled Iloprost Iloprost is a prostacyclin analogue administered by inhalation or the intravenous route. The pulmonary vasodilating effects of inhaled iloprost lasts nearly 45 minutes, therefore six to nine inhalations daily are needed, with each of them requiring approximately 30 minutes [223,224]. Common side effects of treatment were cough, flushing, jaw pain and headache [223]. In the AIR study [223] conducted in at 37 European pulmonary hypertension centers, study participants (idiopathic PAH, PAH associated to systemic sclerosis, anorexigen associated PAH or non operable CTEPH) in functional class III or IV were assessed during a three month period. Patients received a daily inhalation of $2.5 \mu \mathrm{g}$ or $5.0 \mu \mathrm{g}$ of iloprost 6 or 9 times a day or placebo. After 3 months of treatment, 17\% of patients receiving iloprost reached the combined endpoint of improvement in functional class and $10 \%$ gain in 6-MWD as compared to $5 \%$ in the placebo group.

\section{Endothelin receptors antagonists}

Endothelin-1 (ET-1) is a potent vasoconstrictor and therefore plays an important role in the pathogenesis of $\mathrm{PAH}$. In addition, it is responsible for smooth muscle cell proliferation [158]. Elevated ET-1 plasma levels are found in patients suffering from $\mathrm{PAH}$ and are correlated with poor prognosis. There are two existing isoforms of ET-1 receptors: endothelin A (ETRA) and endothelin B (ETRB). Activation of ETRA and ETRB on pulmonary artery smooth muscle cells induce proliferation and vasoconstriction, whereas activation of ETRB on pulmonary endothelial cells leads to release of NO and prostacyclin and participate to the clearance of circulating ET-1. 
Bosentan Bosentan is an oral active dual ETRA and ETRB antagonist. Bosentan has been evaluated in PAH (idiopathic, associated with CTD, and Eisenmenger's syndrome) in five RCT's (Pilot, BREATHE-1, BREATHE-2, BREATHE-5, and EARLY) that have shown improvement in exercise capacity, functional class, haemodynamic, echocardiographic and Doppler variables, and time to clinical worsening [107,225-228]. The first placebocontrolled study included 32 patients affected by idiopathic PAH or scleroderma presenting with PAH showing significant exercise improvement with a gain of 76 meters after three months of treatment with bosentan as compared to placebo [225].

The BREATHE 1 study confirmed the efficacity of treatment with Bosentan in more than 200 assessed patients in NYHA functional class III or IV compared to placebo in a three month trial. After three months of treatment with bosentan, improvements in NYHA functional class were observed in $42 \%$ of patients receiving bosentan compared with $30 \%$ in the placebo arm. 6MWD was improved overall to 44 meters in favor of bosentan. Furthermore, delayed time to clinical worsening was also noted as well as better results in dynpnea scores [226]. One accepted common side effect of treatment is increase in liver enzymes; this is why monthly monitoring of liver transaminases is mandatory in all patients receiving bosentan. Treatment is started at a dose of $62.5 \mathrm{mg}$ twice a day and increased to the dose of $125 \mathrm{mg}$ twice daily after one month of treatment.

Subsequently published data of treatment with bosentan suggested persistent improvements in pulmonary hemodynamics, exercise capacity and modified NYHA functional class and possibly survival rate of patients [229-231]. Results from the EARLY study (doubleblind, randomised controlled 6 months trial) showed that the effect of the dual endothelin receptor antagonist bosentan in patients with mildly symptomatic PAH could be beneficial for PAH patients in NYHA functional class II [228].

Ambrisentan Ambrisentan is a selective ETA receptor antagonist administrated once daily at a dose of $5 \mathrm{mg}$ or $10 \mathrm{mg}$. Two large RCTs (ARIES I and II, i.e. Ambrisentan in Pulmonary Hypertension, Randomized, Double blind, Placebo-controlled Multicenter, Efficacy Studies I and II) have demonstrated efficacy on symptoms, haemodynamics and time to clinical worsening of patients with idiopathic PAH and associated to CTD and HIV infection [232]. An extension study of the ARIES study is the recently published ARIES-E study by Klinger and colleagues [233]. They followed patients for a mean period of 60 weeks in where patients underwent hemodynamic evaluation. The authors concluded that treatment with ambrisentan leads to hemodynamic stability in PAH patients.

\section{Phosphodiesterase type-5 inhibitors}

$\mathrm{NO}$ is a potent pulmonary arteries SMC relaxant that disposed vasodilator activity through up-regulation of its associated down-stream signalling molecule, cyclic GMP (cGMP), metabolism of which is dependent on the activation of a number of PDEs [208]. Phosphodiesterase type 3,4 and 5 are the three main types of this enzyme found in pulmonary artery contractive cells. PDE-5 is the most abundantly expressed isoform in pulmonary circulation which was confirmed by several experimental investigations showing a beneficial effect of PDE-5 inhibitors on vascular remodelling and vasodilatation [234,235].

Sildenafil Sildenafil is an oral PDE-5 inhibitor that is available in Europe since 2005 for PAH patients in functional class II-III whereas this drug is licensed in Canada and the USA for patients in functional class IIIV. Basis for the authorization of this drug in the setting of PAH was a large randomized, placebocontrolled trial in which different doses of sildenafil were assessed in 278 patients presenting with idiopathic PAH, PAH related to CTD or congenital systemic to pulmonary shunts surgically corrected. The majority of study patients were in functional class IIIII. After three months of treatment, the mean placebo-adjusted changes in 6-MWD for $20 \mathrm{mg}, 40 \mathrm{mg}$ and $80 \mathrm{mg}$ doses of sildenafil were 45 meters, 46 meters and 50 meters, respectively. Furthermore, significant hemodynamic and functional class improvements were noted in every sildenafil group as compared to placebo. Common side effects of treatment with sildenafil include headache, flushing and dyspepsia but no hepatic enzymes increase was noted as compared with endothelin receptor antagonists. Long term extension data from 222 patients who completed one year of sildenafil monotherapy with a dose of $80 \mathrm{mg}$ three times daily showed encouraging results with a gain in 6-MWD, suggesting a durable treatment effect [236]. However, sildenafil approval in Europe is currently limited to $20 \mathrm{mg}$ three times a day. No data is currently available on the long-term efficacy of this lower dosage.

Tadalafil Another PDE-5 inhibitor is tadalafil which was granted for use in patients with $\mathrm{PAH}$ in Europe and North America in 2009. Galiè and colleagues [237] assessed in the PHIRST trial 405 randomly assigned patients who were either treatment naïve or already receiving bosentan therapy to placebo or one of the several 
proposed doses of tadalafil $2.5 \mathrm{mg}$ or $10 \mathrm{mg}$ or $20 \mathrm{mg}$ or $40 \mathrm{mg}$ once daily for a period of three months. At study completion, patients receiving tadalafil showed an overall mean placebo-correlated increase in 6-MWD of 33 meters [208]. Thus, this increase was dose-dependent, with only the $40 \mathrm{mg}$ dose achieving the prespecified value for statistical significance for improvement. Data analysis of comparative hemodynamic data from 93 patients who underwent repeat $\mathrm{RHC}$ has significant reduction in MPAP and PVR under treatment with tadalafil. Barst and co-authors [238] underlined favourable effects with tadalafil $40 \mathrm{mg}$ among patients receiving background bosentan, although improvements were less marked compared with treatment naïve cohort.

\section{Combination therapy}

Another therapeutic option is to combine drugs with different mechanisms of action, in order to optimize clinical benefit while minimizing side effects. The two possible strategies for combination therapy are either to add a new medication to an ongoing treatment (sequential combination) or in first intention by starting from the beginning with a combination treatment. The BREATHE-2 trial compared the association of i.v. epoprostenol and oral bosentan with i.v. epoprostenol and placebo among 33 patients with severe PAH over a 12 weeks period [227]. Reduction in pulmonary vascular resistance was greater with combination therapy, although it did not reached statistical significance. Furthermore, no benefit could be shown on the 6-MWD with combination therapy compared to epoprostenol alone (+ $68 \mathrm{~m}$ and $+74 \mathrm{~m}$, respectively). These results however may be related to the small number of patients and the short term follow up in the context of the addition of a treatment to a drug already known to bring an important benefit in severe $\mathrm{PAH}$ patients. In a recent controlled trial, the sequential addition of oral sildenafil $80 \mathrm{mg}$ three times daily for patients already receiving i.v. epoprostenol with insufficient improvement, proved to be more effective than the placebo on the 6-MWD and hemodynamic parameters. Indeed, there was a significant reduction in the number of patients showing clinical worsening and an improvement of survival among most severe patients [239]. There is currently no data on the addition of bosentan in such context. The combination of iloprost to bosentan in patients with idiopathic $\mathrm{PAH}$ or associated PAH in NYHA functional class III was shown to be significantly better than placebo and bosentan in terms of 6-MWD (+ $26 \mathrm{~m})$, NYHA functional class and on post inhalation hemodynamic parameters (PVR -26.4\%) [240].

Several uncontrolled studies evaluated the efficacy of other associations with encouraging results. The open- label sequential addition of bosentan or sildenafil to epoprostenol, treprostinil or iloprost was shown to be of interest [241-243]. Also, the association of ERA and PDE5, both available in oral form, offers an interesting option [244,245]. Currently, the limited data precludes consensus on which combined treatment or strategy should be preferred. Also, no long term evaluation of combination therapy is available.

The best strategy of combination therapy should be discussed in the next world symposium of Pulmonary Hypertension. Current ERS/ESC guidelines propose sequential combination therapy without any recommendation regarding the best way to associate available specific PAH therapies.

\section{Potential future therapies Macitentan}

Macitentan, also called ACT-064992, is a novel, highly potent, tissue-targeting dual ET-1 receptor antagonist characterized by a high lipophilicity [247]. Macitentan has been tested in the largest, long-term, event-driven randomized, controlled study (SERAPHIN, Study with an Endothelin Receptor Antagonist in Pulmonary arterial Hypertension to Improve clinical outcome) [246]. The Seraphin study was designed to evaluate the efficacy and safety of macitentan through the primary endpoint of time to first morbidity and all-cause mortality event in 742 patients with symptomatic PAH. Patients were treated for up to three and a half years.

Macitentan has met its primary endpoint, decreasing the risk of a morbidity/mortality event over the treatment period versus placebo. Secondary efficacy endpoints, including change from baseline to month six in 6-MWD, change from baseline to month six in NYHA FC and time - over the whole treatment period - to either death due to PAH or hospitalization due to $\mathrm{PAH}$, also showed a dose-dependent effect. Treatment with macitentan in this study was well tolerated; headache, nausea and vomiting were reported as minor adverse events [248]. The safety set comprised 741 patients, who received at least one dose of study treatment (placebo, $3 \mathrm{mg}$ or $10 \mathrm{mg}$ ). The number of adverse events reported and patients discontinuing treatment due to adverse events was similar across all groups. Similar elevations of liver aminotransferases greater than three times the upper limit of normal were observed in all groups. In addition, no difference was observed between macitentan and placebo in terms of fluid retention (edema). A decrease in hemoglobin reported as an adverse event - was observed more frequently on macitentan than placebo, with no difference in treatment discontinuation between groups.

\section{Vardenafil}

Vardenafil is another PDE5 inhibitor. Recently published data from a prospective, randomised study including 66 
patients with PAH suggests improvement in 6-MWD and hemodynamic parameters after 3 months of treatment with vardenafil as compared to placebo. Side effects are not reported and proposed dosage is $5 \mathrm{mg}$ twice daily [249]. However, further studies are needed.

\section{Riociguat}

Endothelium-derived NO regulates vascular homeostasis through pulmonary arteries SMC relaxation via the activation of the second messenger cGMP. The clinical benefits associated with the PDE-5 inhibitor class has led to interest in testing whether other agents that modulate NO signaling might be similarly beneficial in PAH. Riociguat is a firstin-class drug that augments cGMP biosynthesis through direct stimulation of the enzyme soluble guanylate cyclase (sGC) promoting vasodilatation by direct stimulation of sGC in an NO-independent fashion, and by sensitization of sGC to low endogenous NO levels [250].

A phase I randomized placebo-controlled study in 58 healthy male subjects were given riociguat orally was designed to test the safety profile, pharmacokinetics and pharmacodynamics of single oral doses of riociguat (0.25-5 mg). A proof-of-concept study was conducted to investigate oral riociguat in patients with moderate to severe $\mathrm{PH}$ in a two-part, non-randomized, open-label, single center trial [251]. Riociguat was well tolerated in doses up to $2.5 \mathrm{mg}$, whereas $5 \mathrm{mg}$ caused asymptomatic hypotension in one patient. Therefore the $2.5 \mathrm{mg}$ dose was used in the second part of the trial to demonstrate efficacy. Riociguat significantly reduced mPAP, PVR and systemic vascular resistance and increased cardiac index [251]. Results from a multicenter, open-label, uncontrolled phase II trial involving 75 patients with $\mathrm{PAH}$ $(\mathrm{n}=33)$ and chronic thrombo-embolic PH $(\mathrm{n}=42)$ showed that 12 weeks of oral riociguat given 3 times daily conferred improvements in symptoms, NYHA FC, exercise capacity, NT-proBNP level, and pulmonary hemodynamics [252]. Riociguat is also under investigation in other form of $\mathrm{PH}$ as $\mathrm{PH}$ associated with chronic obstructive pulmonary disease, with interstitial lung disease or with left ventricular dysfunction [253-255].

The Phase III, double-blind, randomized, placebocontrolled PATENT-1 study investigated the efficacy and safety of riociguat in patients with symptomatic PAH [256]. Treatment-naïve patients and patients pre-treated with ERAs or prostacyclin analogues were eligible. Riociguat was titrated from a starting dose of $1 \mathrm{mg}$ three times daily (t.i.d.) [range $0.5-2.5 \mathrm{mg}$ t.i.d.]. The primary outcome was the change from baseline in 6-MWD at week 12. Secondary endpoints included the change from baseline in pulmonary vascular resistance (PVR), NTproBNP, NYHA FC, clinical worsening, living with $\mathrm{PH}$ questionnaire and Borg dyspnea score. A total of 445 patients were randomized. Preliminary analysis showed a significant increase in 6-MWD from baseline of $35.8 \mathrm{~m}$ with riociguat versus placebo $(95 \%$ CI $20.1-51.5 \mathrm{~m}, \mathrm{p}<$ $0.0001)$. Predefined exploratory analyses indicated that riociguat improved 6-MWD in pretreated patients $(+35.7 \mathrm{~m}$ [95\% CI $15.0-56.3 \mathrm{~m}])$ as well as treatment naïve patients $(+38.4 \mathrm{~m}$ [95\% CI 14.5-62.3 m]). Significant improvements were also seen in PVR $(\mathrm{p}<0.0001)$, NT-proBNP $(\mathrm{p}<0.0001)$, functional class $(\mathrm{p}=0.003)$, clinical worsening $(\mathrm{p}=0.0046)$, living with $\mathrm{PH}$ questionnaire $(\mathrm{p}=0.002)$ and Borg dyspnea score $(\mathrm{p}=0.002)$. Riociguat was well tolerated and had a favorable safety profile. Thus, riociguat may represent a new treatment option for patients with PAH. An open-label extension study (PATENT-2) will evaluate the long-term safety of riociguat in patients with $\mathrm{PAH}$.

\section{Selexipag}

Selexipag is an orally active prodrug metabolized to the highly selective prostacyclin IP receptor agonist ACT-333679 (previously known as MRE-269), which has a half-life of over $6 \mathrm{~h}$ [257]. With in high selectivity for the IP receptor over other prostanoid receptors (at least 130-fold selectivity), selexipag can be distinguished from beraprost or iloprost currently used in the management of PAH [258]. With no affinity for the prostaglandin $\mathrm{E}$ receptor 3 (EP3), selexipag exerts similar vasodilatory activity on both large and small pulmonary arterial branches [259] and its relaxant efficacy is not modified under conditions associated with $\mathrm{PAH}$, whereas relaxation to treprostinil may be limited in the presence of mediators of disease such as ET-1 [260]. Preclinical study results showed that twice-daily administration of selexipag attenuates right ventricular hypertrophy, improves pulmonary hemodynamics, and significantly increases survival in MCT-treated PH rats [259].

A phase II study, involving $43 \mathrm{PAH}$ patients showed that treatment with selexipag for 17 weeks conferred significant improvements in PVR $(-30.3 \%$ versus placebo) compared with placebo [261]. Treatment with selexipag was well tolerated by most patients in this study. Adverse events were consistent with the known side effect profile of IPr agonism such as headache, pain in extremity, pain in jaw, nausea, and diarrhea. These side effects decreased over time in patients treated with selexipag [261].

A phase III randomized trial GRIPHON [262] to examine the effect of selexipag on morbidity and mortality in PAH is underway and will afford more information regarding efficacy and safety of selexipag.

\section{Tyrosine kinase inhibitors}

One of the most promising targets in PAH is plateletderived growth factor (PDGF). PDGF has been 
implicated in endothelial cell dysfunction and proliferation and migration of smooth muscle cells. It has been suggested that PDGF may play a role in PAH [263-265]. Pulmonary vascular remodelling in different animal models of PAH was shown to regress with the administration of imatinib mesylate $\left(\right.$ Gleevec $\left.^{\oplus}\right)$, a PDGF receptors antagonist approved for the treatment of chronic myeloid leukaemia [266]. Moreover, case reports suggest a beneficial effect of imatinib among severe PAH patients and a first randomized (imatinib vs placebo), double-blind, 24 weeks Phase II study was performed in 59 PAH patients in NYHA functional class II to IV receiving specific PAH therapies [267]. The primary endpoint (6-MWD after 24 weeks) was not different between 2 groups $(+22 \mathrm{~m}$ in imatinib group as compared to placebo) even if a significant improvement of hemodynamic parameters was observed, especially among the patients with the most severe hemodynamic compromise [267]. This preliminary study does not allow concluding on the potential benefits of imatinib in $\mathrm{PAH}$, but led to development of a phase III clinical trial (IMPRES) evaluating imatinib in a randomized controlled double-blind trial of 24-week, in 202 severe PAH patients treated with at least two PAH specific drugs. After 24 weeks, a significant improvement in the primary endpoint, 6MWD, was observed (+32 $\mathrm{m}$ in imatinib group vs. placebo) as well as an improvement of secondary endpoints including hemodynamic parameters [268]. However, several cases of subdural hematoma were reported in patients treated with imatinib: 2 cases in the double-blind period of 24 weeks and 7 supplemental cases in an openlabel extension phase of the study. The mechanism of these subdural hematomas is not elucidated and the high incidence observed may be partly favored by anticoagulation recommended for PAH patients. Subdural hematoma is a complication of imatinib previously reported in other settings where it has been used, including oncology or pulmonary fibrosis. Netherless, this complication has rarely been reported in previous clinical trials in PAH or in registries. In addition, it has been demonstrated that tyrosine kinase inhibitors, including imatinib, may have possible cardiac adverse effects on long term use that might limit its benefice in PAH [269]. According to these results, the benefit/risk ratio of imatinib in PAH was not considered to be sufficient and to date, the use imatinib was not recommended in PAH.

\section{Non medical treatment}

\section{Balloon atrial septostomy}

The presence of a right-left shunt, secondary to congenital cardiac malformation, or a patent foramen oval, among patients with severe $\mathrm{PAH}$, seems to carry a better prognosis [270]. Atrioseptostomy is an artificial communication interauricular to decrease the right heart volume, subjected to a high after load secondary to increased pulmonary resistances [271]. The surgical creation of a right-left shunt decreases right auricular pressure and increases systemic blood flow, later on, reduction in right ventricular wall tension is expected [271]. Thus, in spite of arterial desaturation induced by the shunt, oxygen delivery is improved [271]. Atrioseptostomy has however never been studied in controlled clinical trials. However, several experienced teams reported their data and it seems that immediate mortality is high, reaching $14 \%$ during the first week, particularly in the case of severe desaturation and right heart failure [105,271-273]. Among patients who survived, clinical improvement with regression of symptoms and gain of functional capacity can be observed. Atrioseptostomy should only be carried out in centers with significant experience, both in performance of atrioseptostomy and management of $\mathrm{PAH}$ patients, especially post interventional. The impact of balloon atrial septostomy on long term survival has not been established in RCTs [271,274].

\section{Lung transplantation}

Lung transplantation was historically the treatment of choice for severe PAH and remains treatment of choice if medical treatments are insufficient [197]. However, this particularly heavy surgery can be proposed only to a minority of patients suffering from $\mathrm{PAH}$. Moreover, long-term benefits remain disappointing with approximately 50\% survival at 5 years [275]. Early mortality is mainly related to infectious complications whereas late mortality reflects mostly chronic rejection such as obliterating bronchiolitis. Mono-pulmonary transplantation had good long-term results [276,277], but most centers currently prefer bi-pulmonary transplantation which has less post-operative complications [278]. Cardiopulmonary transplantation may be necessary for patients presenting with terminal right heart failure or complex congenital heart disease [279]. In conclusion, PAh is a rare group of diseases that shares broadly similar pathological features, pathophysiology and clincal presentation. The discovery of the central role of endothelial dysfunction leads to the development of specific PAH therapies including prostanoids, endothelin receptor antagonists and PDE-5 inhibitors. Even these therapeutic advances, no cure of the disease can be achieved and the prognosis remains unsatisfactory.

\footnotetext{
Abbreviations

ALK-1: Activin A receptor type II-like kinase-1; BMPR2: Bone morphogenetic protein receptor 2; CCB: Calcium channel blockers; CHD: Congenital heart diseases; Chest HRCT: Chest High resolution computed tomography;

$\mathrm{Cl}$ : Cardiac index; CMR: Cardiac magnetic resonance imaging; CO: Cardiac output; CTD: Connective tissue disease; CPET: Cardiopulmonary exercise testing; CTEPH: Chronic thrombo-embolic pulmonary hypertension; DLCO: Diffusing lung capacity of carbon monoxide; DLCONA: Diffusing lung capacity of carbon monoxide/alveolar volume; ESC: European Society of
} 
Cardiology; ERS: European Respiratory Society; HHC: Hereditary hemorrhagic telangiectasia; HIV: Human immunodeficiency virus; INR: International Normalized Ratio; NIH: National Institute of Health; NO: Nitric oxide; NYHA: New York Heart Association; PAH: Pulmonary arterial hypertension; PFT: Pulmonary function test; mPAP: Mean pulmonary arterial pressure; PCWP: Pulmonary capillary wedge pressure; PVOD: Pulmonary veno-occlusive disease; PVR: Pulmonary Vascular Resistance; RAP: Right atrial pressure; PaO2: Partial pressure of arterial oxygen; $\mathrm{PaCO} 2$ : Partial pressure of arterial carbon dioxide; PDGF: Platelet-Derived Growth Factor; RCT: Randomized clinical trial; RHC: Right heart catheterization; SpO2: Pulse arterial oxygen saturation; SR: Sex ratio; SvO2: Mixed venous oxygen saturation; TTE: Transthoracic Doppler-echocardiography; TKI: tyrosine kinsase inhibitor; TLC: Total lung capacity; TPR: Total Pulmonary Resistance; TGF: beta Transforming growth factor beta; VEGF: Vascular endothelial growth factor; 6-MWD: 6-minute walk distance.

\section{Competing interests}

D Montani, X Jaïs, L Savale, M Humbert, G Simonneau and O Sitbon have been supported by Actelion, Bayer Schering, GlaxoSmithKline, Novartis, Pfizer, Inc., Lilly \& Co., and United Therapeutics for consultancy services and as members of their scientific advisory boards. The other authors declare that they have no competing interests.

\section{Authors' contributions}

$\mathrm{DM}, \mathrm{SG}, \mathrm{PD}, \mathrm{FP}, \mathrm{BG}, \mathrm{GG}, \mathrm{XJ}, \mathrm{LS}, \mathrm{EAM}, \mathrm{LCP}, \mathrm{MH}, \mathrm{GS}$, OS participated in drafting the manuscript. All authors read and approved the final manuscript.

\section{Author details}

'Univ. Paris-Sud, Faculté de Médecine, Kremlin-Bicêtre F-94270, France. ${ }^{2}$ AP-HP, DHU TORINO, Centre de Référence de l'Hypertension Pulmonaire Sévère, Service de Pneumologie et Réanimation Respiratoire, Hôpital Bicêtre, Le Kremlin-Bicêtre F-94270, France. ${ }^{3}$ INSERM U999, Labex LERMIT, Hypertension Artérielle Pulmonaire: Physiopathologie et Innovation Thérapeutique, Centre Chirurgical Marie Lannelongue, Le Plessis-Robinson F-92350, France. ${ }^{4}$ Pulmonary Hypertension Service, Royal Brompton Hospital, London SW3 6NP, UK.

Received: 9 April 2013 Accepted: 12 June 2013

Published: 6 July 2013

\section{References}

1. Rubin L: Primary pulmonary hypertension. N Engl J Med 1997, 336(2):111-7.

2. Simonneau $\mathrm{G}$, et al: Updated clinical classification of pulmonary hypertension. J Am Coll Cardiol 2009, 54(1 Suppl):S43-54

3. Wagenvoort CA, Wagenvoort N: Primary pulmonary hypertension: a pathological study of the lung vessels in 156 clinically diagnosed cases. Circulation 1970, 42:1163-84.

4. Hatano S, Strasser T: Primary Pulmonary Hypertension. Report on a WHO meeting. October 15-17, 1973. Geneva: WHO; 1975.

5. Fishman AP: Clinical classification of pulmonary hypertension. Clin Chest Med 2001, 22(3):385-91. vii.

6. Cogan JD, et al: High frequency of BMPR2 exonic deletions/duplications in familial pulmonary arterial hypertension. Am J Respir Crit Care Med 2006, 174(5):590-8.

7. Aldred MA, et al: BMPR2 gene rearrangements account for a significant proportion of mutations in familial and idiopathic pulmonary arterial hypertension. Hum Mutat 2006, 27(2):212-3.

8. Shintani $M$, et al: A new nonsense mutation of SMAD8 associated with pulmonary arterial hypertension. J Med Genet 2009, 46(5):331-7.

9. Nasim MT, et al: Molecular genetic characterization of SMAD signaling molecules in pulmonary arterial hypertension. Hum Mutat 2011, 2011:2011.

10. Austin $E D$, et al: Whole exome sequencing to identify a novel gene (caveolin-1) associated with human pulmonary arterial hypertension. Circ Cardiovasc Genet 2012, 5(3):336-43.

11. Machado RD, et al: Mutations of the TGF-beta type II receptor BMPR2 in pulmonary arterial hypertension. Hum Mutat 2006, 27(2):121-32.

12. Thomson JR, et al: Sporadic primary pulmonary hypertension is associated with germline mutations of the gene encoding BMPR-II, a receptor member of the TGF-ß family. J Med Genet 2000, 37:741-5.
13. Chaouat $A$, et al: Endoglin germline mutation in a patient with hereditary haemorrhagic telangiectasia and dexfenfluramine associated pulmonary arterial hypertension. Thorax 2004, 59(5):446-8.

14. Trembath RC, et al: Clinical and molecular genetic features of pulmonary hypertension in patients with hereditary hemorrhagic telangiectasia. N Engl I Med 2001, 345(5):325-34.

15. Galie N, et al: Guidelines for the diagnosis and treatment of pulmonary hypertension. Eur Respir J 2009, 34(6):1219-63.

16. Simonneau $\mathrm{G}$, et al: Clinical classification of pulmonary hypertension. J Am Coll Cardiol 2004, 43(12 Suppl S):5S-12S.

17. Souza $R$, et al: Pulmonary arterial hypertension associated with fenfluramine exposure: report of 109 cases. Eur Respir J 2008, 31(2):343-8.

18. Rich $S$, et al: Anorexigens and pulmonary hypertension in the United States: results from the surveillance of North American pulmonary hypertension. Chest 2000, 117(3):870-4.

19. Walker $A M$, et al: Temporal trends and drug exposures in pulmonary hypertension: an American experience. Am Heart J 2006, 152(3):521-6.

20. Frachon I, et al: Benfluorex and unexplained valvular heart disease: a case-control study. PloS One 2010, 5(4):e10128.

21. Savale $L$, et al: Pulmonary hypertension associated with benfluorex exposure. Eur Respir J 2012, 40(5):1164-72.

22. Chin KM, Channick RN, Rubin L: Is methamphetamine use associated with idiopathic pulmonary arterial hypertension? Chest 2006, 130(6):1657-63.

23. Montani $\mathrm{D}$, et al: Pulmonary arterial hypertension in patients treated by dasatinib. Circulation 2012, 125(17):2128-37.

24. Hachulla E, et al: Early detection of pulmonary arterial hypertension in systemic sclerosis: a French nationwide prospective multicenter study. Arthritis Rheum 2005, 52(12):3792-800.

25. Mukerjee $D$, et al: Prevalence and outcome in systemic sclerosis associated pulmonary arterial hypertension: application of a registry approach. Ann Rheum Dis 2003, 62(11):1088-93.

26. Launay $\mathrm{D}$, et al: Prevalence and characteristics of moderate to severe pulmonary hypertension in systemic sclerosis with and without interstitial lung disease. J Rheumatol 2007, 34(5):1005-11.

27. de Groote $\mathrm{P}$, et al: Evaluation of cardiac abnormalities by Doppler echocardiography in a large nationwide multicentric cohort of patients with systemic sclerosis. Ann Rheum Dis 2008, 67(1):31-6.

28. Meune $C$, et al: Cardiac involvement in systemic sclerosis assessed by tissue-doppler echocardiography during routine care: A controlled study of 100 consecutive patients. Arthritis Rheum 2008, 58(6):1803-9.

29. Kim KK, Factor SM: Membranoproliferative glomerulonephritis and plexogenic pulmonary arteriopathy in a homosexual man with acquired immunodeficiency syndrome. Hum Pathol 1987, 18(12):1293-6.

30. Mehta NJ, et al: HIV-Related pulmonary hypertension: analytic review of 131 cases. Chest 2000, 118(4):1133-41.

31. Opravil M, et al: HIV-associated primary pulmonary hypertension. A case control study. Swiss HIV Cohort Study. Am J Respir Crit Care Med 1997, 155(3):990-5.

32. Sitbon $\mathrm{O}$, et al: Prevalence of HIV-related pulmonary arterial hypertension in the current antiretroviral therapy era. Am J Respir Crit Care Med 2008, 177(1):108-13

33. Herve $\mathrm{P}$, et al: Pulmonary vascular disorders in portal hypertension. Eur Respir J 1998, 11(5):1153-66.

34. Rodriguez-Roisin R, et al: Pulmonary-Hepatic vascular Disorders (PHD). Eur Respir J 2004, 24(5):861-880.

35. Hadengue $A$, et al: Pulmonary hypertension complicating portal hypertension: prevalence and relation to splanchnic hemodynamics. Gastroenterology 1991, 100(2):520-8.

36. Krowka MJ, et al: Portopulmonary hypertension: Results from a 10-year screening algorithm. Hepatology 2006, 44(6):1502-10.

37. Eisenmenger $\mathrm{V}$ : Die angeborene defecte der kammersheidewand des herzen. Z Klin Med 1897:132-1.

38. Wood $\mathrm{P}$ : The Eisenmenger syndrome or pulmonary hypertension with reversed central shunt. Br Med J 1958, 2:701-712.

39. Daliento $L$, et al: Eisenmenger syndrome. Factors relating to deterioration and death. Eur Heart J 1998, 19(12):1845-55.

40. Besterman E: Atrial Septal Defect with Pulmonary Hypertension. Br Heart 1961, 23(5):587-598.

41. Hoffman Jl, Rudolph AM: The natural history of ventricular septal defects in infancy. Am J Cardiol 1965, 16(5):634-53. 
42. Lapa MS, et al: [Clinical characteristics of pulmonary hypertension patients in two reference centers in the city of Sao Paulo]. Rev Assoc Med Bras 2006, 52(3):139-43.

43. Chaves $\mathrm{E}$ : The pathology of the arterial pulmonary vasculature in manson's schistosomiasis. Dis Chest 1966, 50(1):72-7.

44. de Cleva $R$, et al: Prevalence of pulmonary hypertension in patients with hepatosplenic Mansonic schistosomiasis-prospective study. Hepatogastroenterology 2003, 50(54):2028-30.

45. Lapa M, et al: Cardiopulmonary manifestations of hepatosplenic schistosomiasis. Circulation 2009, 119(11):1518-23.

46. Castro O, Hoque M, Brown BD: Pulmonary hypertension in sickle cell disease: cardiac catheterization results and survival. Blood 2003, 101(4):1257-61.

47. Gladwin MT, et al: Pulmonary Hypertension as a Risk Factor for Death in Patients with Sickle Cell Disease. N Engl J Med 2004, 350(9):886-895.

48. Aessopos A, et al: Pulmonary hypertension and right heart failure in patients with beta-thalassemia intermedia. Chest 1995, 107(1):50-3.

49. Smedema JP, Louw VJ: Pulmonary arterial hypertension after splenectomy for hereditary spherocytosis. Cardiovasc J Afr 2007, 18(2):84-9.

50. Jais $X$, et al: An extreme consequence of splenectomy in dehydrated hereditary stomatocytosis: gradual thrombo-embolic pulmonary hypertension and lung-heart transplantation. Hemoglobin 2003, 27(3):139-47.

51. Stuard ID, Heusinkveld RS, Moss AJ: Microangiopathic hemolytic anemia and thrombocytopenia in primary pulmonary hypertension. N Engl J Med 1972, 287(17):869-70.

52. Parent $F$, et al: A hemodynamic study of pulmonary hypertension in sickle cell disease. N Engl J Med 2011, 365(1):44-53.

53. Montani $\mathrm{D}$, et al: Pulmonary veno-occlusive disease: clinical, functional, radiologic, and hemodynamic characteristics and outcome of 24 cases confirmed by histology. Medicine (Baltimore) 2008, 87(4):220-33.

54. Lantuejoul S, et al: Pulmonary veno-occlusive disease and pulmonary capillary hemangiomatosis: a clinicopathologic study of 35 cases. Am J Surg Pathol 2006, 30(7):850-7.

55. Resten A, et al: Pulmonary hypertension: $C T$ of the chest in pulmonary venoocclusive disease. AJR Am J Roentgenol 2004, 183(1):65-70.

56. Holcomb BW Jr, et al: Pulmonary veno-occlusive disease: a case series and new observations. Chest 2000, 118(6):1671-9.

57. Dufour B, et al: High-resolution CT of the chest in four patients with pulmonary capillary hemangiomatosis or pulmonary venoocclusive disease. AJR Am J Roentgenol 1998, 171(5):1321-4.

58. Montani D, et al: Pulmonary veno-occlusive disease. Eur Respir J 2009, 33(1):189-200.

59. Rabiller A, et al: Occult alveolar haemorrhage in pulmonary venoocclusive disease. Eur Respir J 2006, 27(1):108-13.

60. Oudiz RJ: Pulmonary hypertension associated with left-sided heart disease. Clin Chest Med 2007, 28(1):233-41.

61. Abramson SV, et al: Pulmonary hypertension predicts mortality and morbidity in patients with dilated cardiomyopathy. Ann Intern Med 1992 116(11):888-95.

62. Zener $\mathrm{JC}$, et al: Regression of extreme pulmonary hypertension after mitral valve surgery. Am J Cardiol 1972, 30(8):820-6.

63. Braunwald $E$, et al: Effects of Mitral-Valve Replacement on the Pulmonary Vascular Dynamics of Patients with Pulmonary Hypertension. N Engl J Med 1965, 273:509-14.

64. Delgado JF, et al: Pulmonary vascular remodeling in pulmonary hypertension due to chronic heart failure. Eur J Heart Fail 2005, 7(6):1011-6.

65. Moraes DL, Colucci WS, Givertz MM: Secondary pulmonary hypertension in chronic heart failure: the role of the endothelium in pathophysiology and management. Circulation 2000, 102(14):1718-23.

66. Fraser $\mathrm{KL}$, et al: Pulmonary hypertension and cardiac function in adult cystic fibrosis: role of hypoxemia. Chest 1999, 115(5):1321-8.

67. Cottin $V$, et al: Combined pulmonary fibrosis and emphysema: a distinct underrecognised entity. Eur Respir J 2005, 26(4):586-93.

68. Weitzenblum E, et al: Prognostic value of pulmonary artery pressure in chronic obstructive pulmonary disease. Thorax 1981, 36(10):752-8.

69. Thabut $\mathrm{G}$, et al: Pulmonary hemodynamics in advanced COPD candidates for lung volume reduction surgery or lung transplantation. Chest 2005, 127(5):1531-6.
70. Chaouat $A$, et al: Severe pulmonary hypertension and chronic obstructive pulmonary disease. Am J Respir Crit Care Med 2005, 172(2):189-94.

71. Tapson VF, Humbert M: Incidence and prevalence of chronic thromboembolic pulmonary hypertension: from acute to chronic pulmonary embolism. Proc Am Thorac Soc 2006, 3(7):564-7.

72. Pengo $V$, et al: Incidence of chronic thromboembolic pulmonary hypertension after pulmonary embolism. N Engl J Med 2004, 350(22):2257-64

73. Kim NH: Assessment of operability in chronic thromboembolic pulmonary hypertension. Proc Am Thorac Soc 2006, 3(7):584-8.

74. Dartevelle $P$, et al: Chronic thromboembolic pulmonary hypertension. Eur Respir J 2004, 23(4):637-48.

75. Jamieson SW, et al: Pulmonary endarterectomy: experience and lessons learned in 1,500 cases. Ann Thorac Surg 2003, 76(5):1457-62. discussion 1462-4.

76. Suntharalingam J, et al: Long-term use of sildenafil in inoperable chronic thromboembolic pulmonary hypertension. Chest 2008, 134(2):229-36.

77. Jais $X$, et al: Immunosuppressive therapy in lupus- and mixed connective tissue disease-associated pulmonary arterial hypertension: a retrospective analysis of twenty-three cases. Arthritis Rheum 2008, 58(2):521-31.

78. Rubin $L$, et al: Current and future management of chronic thromboembolic pulmonary hypertension: from diagnosis to treatment responses. Proc Am Thorac Soc 2006, 3(7):601-7.

79. Dingli $D$, et al: Unexplained pulmonary hypertension in chronic myeloproliferative disorders. Chest 2001, 120(3):801-8.

80. Guilpain P, et al: Pulmonary Hypertension Associated with Myeloproliferative Disorders: A Retrospective Study of Ten Cases. Respiration 2008, 76:295-302.

81. Marvin KS, Spellberg RD: Pulmonary hypertension secondary to thrombocytosis in a patient with myeloid metaplasia. Chest 1993, 103(2):642-4.

82. Nand S, Orfei E: Pulmonary hypertension in polycythemia vera. Am J Hematol 1994, 47(3):242-4.

83. Peacock AJ: Pulmonary hypertension after splenectomy: a consequence of loss of the splenic filter or is there something more? Thorax 2005, 60(12):983-4.

84. Gluskowski J, et al: Pulmonary haemodynamics at rest and during exercise in patients with sarcoidosis. Respiration 1984, 46(1):26-32.

85. Bourbonnais JM, Samavati L: Clinical predictors of pulmonary hypertension in sarcoidosis. Eur Respir J 2008, 32(2):296-302.

86. Handa T, et al: Incidence of pulmonary hypertension and its clinical relevance in patients with sarcoidosis. Chest 2006, 129(5):1246-52.

87. Nunes $\mathrm{H}$, et al: Pulmonary hypertension associated with sarcoidosis: mechanisms, haemodynamics and prognosis. Thorax 2006, 61(1):68-74

88. Dauriat $G$, et al: Lung transplantation for pulmonary langerhans' cell histiocytosis: a multicenter analysis. Transplantation 2006, 81(5):746-50.

89. Fartoukh $M$, et al: Severe pulmonary hypertension in histiocytosis X. Am J Respir Crit Care Med 2000, 161(1):216-23.

90. Harari $\mathrm{S}$, et al: Advanced pulmonary histiocytosis $\mathrm{X}$ is associated with severe pulmonary hypertension. Chest 1997, 111(4):1142-4.

91. Cottin $V$, et al: Pulmonary hypertension in lymphangioleiomyomatosis: characteristics in 20 patients. Eur Respir J 2012, 40(3):630-40.

92. Montani $D$, et al: Pulmonary hypertension in patients with neurofibromatosis type I. Medicine (Baltimore) 2011, 90(3):201-11.

93. Hamaoka $\mathrm{K}$, et al: Pulmonary hypertension in type I glycogen storage disease. Pediatr Cardiol 1990, 11(1):54-6.

94. Inoue $S$, et al: [Pulmonary hypertension due to glycogen storage disease type II (Pompe's disease): a case report]. J Cardiol 1989, 19(1):323-32.

95. Humbert $M$, et al: Pulmonary arterial hypertension and type-I glycogen-storage disease: the serotonin hypothesis. Eur Respir J 2002, 20(1):59-65.

96. Pizzo CJ: Type I glycogen storage disease with focal nodular hyperplasia of the liver and vasoconstrictive pulmonary hypertension. Pediatrics 1980, 65(2):341-3

97. Elstein D, et al: Echocardiographic assessment of pulmonary hypertension in Gaucher's disease. Lancet 1998, 351(9115):1544-6.

98. Lee R, Yousem S: The frequency and type of lung involvement in patients with Gaucher's disease. Lab Invest 1998, 58:54. A (Abstract).

99. Theise ND, Scheuer PJ, Grundy JE: Cytomegalovirus and autoimmune liver disease. J Clin Pathol 1989, 42(12):1310-1. 
100. Chu JW, et al: High prevalence of autoimmune thyroid disease in pulmonary arterial hypertension. Chest 2002, 122(5):1668-73.

101. Mayer $E$, et al: Surgical treatment of pulmonary artery sarcoma. $J$ Thorac Cardiovasc Surg 2001, 121(1):77-82.

102. Anderson $M B$, et al: Primary pulmonary artery sarcoma: a report of six cases. Ann Thorac Surg 1995, 59(6):1487-90.

103. Mussot $S$, et al: Retrospective institutional study of 31 patients treated for pulmonary artery sarcoma. Eur J Cardiothorac Surg 2013, 43(4):787-93.

104. Yigla $M$, et al: Pulmonary hypertension in patients with end-stage renal disease. Chest 2003, 123(5):1577-82.

105. Rich $\mathrm{S}$, et al: Primary pulmonary hypertension. A national prospective study. Ann Intern Med 1987, 107(2):216-23.

106. D'Alonzo GE, et al: Survival in patients with primary pulmonary hypertension. Results from a national prospective registry. Ann Intern Med 1991, 115(5):343-9.

107. Humbert M, Sitbon $\mathrm{O}$, Simonneau G: Treatment of pulmonary arterial hypertension. N Engl J Med 2004, 351(14):1425-36.

108. Humbert $M$, et al: Pulmonary arterial hypertension in France: results from a national registry. Am J Respir Crit Care Med 2006, 173(9):1023-30.

109. Humbert M, et al: Survival in patients with idiopathic, familial, and anorexigen-associated pulmonary arterial hypertension in the modern management era. Circulation 2010, 122(2):156-63.

110. Benza RL, et al: Predicting survival in pulmonary arterial hypertension: insights from the Registry to Evaluate Early and Long-Term Pulmonary Arterial Hypertension Disease Management (REVEAL). Circulation 2010, 122(2):164-72.

111. Humbert $M$, et al: Bone morphogenetic protein receptor 2 germline mutations in pulmonary arterial hypertension associated with fenfluramine derivatives. Eur Respir J 2002, 20(3):518-523.

112. Machado RD, et al: Genetic association of the serotonin transporter in pulmonary arterial hypertension. Am J Respir Crit Care Med 2006, 173(7):793-7.

113. Thomson J, et al: Familial and sporadic primary pulmonary hypertension is caused by BMPR2 gene mutations resulting in haploinsufficiency of the bone morphogenetic protein type II receptor. J Heart Lung Transplant 2001, 20(2):149.

114. Sztrymf B, et al: Clinical outcomes of pulmonary arterial hypertension in carriers of BMPR2 mutation. Am J Respir Crit Care Med 2008, 177(12):1377-83.

115. Loyd J, et al: Genetic anticipation and abnormal gender ratio at birth in familial primary pulmonary hypertension. Am J Respir Crit Care Med 1995, 152:93-97.

116. Loyd JE, Primm RK, Newman JH: Familial primary pulmonary hypertension: clinical patterns. Am Rev Respir Dis 1984, 129(1):194-7.

117. Deng $Z$, et al: Familial primary pulmonary hypertension (gene PPH1) is caused by mutations in the bone morphogenetic protein receptor-II gene. Am J Hum Genet 2000, 67:737-744.

118. Lane KB, et al: Heterozygous germline mutations in BMPR2, encoding a TGF-beta receptor, cause familial primary pulmonary hypertension. The International PPH Consortium. Nat Genet 2000, 26(1):81-4.

119. Machado RD, et al: Genetics and genomics of pulmonary arterial hypertension. J Am Coll Cardiol 2009, 54(1 Suppl):S32-42.

120. Girerd B, et al: Clinical outcomes of pulmonary arterial hypertension in patients carrying an ACVRL1 (ALK1) mutation. Am J Respir Crit Care Med 2010, 181(8):851-61.

121. Rosenzweig $E B$, et al: Clinical implications of determining BMPR2 mutation status in a large cohort of children and adults with pulmonary arterial hypertension. J Heart Lung Transplant 2008, 27(6):668-74.

122. Aldred MA, et al: Characterization of the BMPR2 5'-untranslated region and a novel mutation in pulmonary hypertension. Am J Respir Crit Care Med 2007, 176(8):819-24.

123. Humbert M: Update in pulmonary hypertension 2008. Am J Respir Crit Care Med 2009. in press.

124. Trembath $\mathrm{R}$, et al: Clinical and molecular genetic features of pulmonary hypertension in hereditary hemorrhagic telangiectasia. $N$ Engl J Med 2001, 345:325-334

125. Abdalla $S A$, et al: Primary pulmonary hypertension in families with hereditary haemorrhagic telangiectasia. Eur Respir J 2004, 23(3):373-7.

126. Harrison RE, et al: Molecular and functional analysis identifies ALK-1 as the predominant cause of pulmonary hypertension related to hereditary haemorrhagic telangiectasia. J Med Genet 2003, 40(12):865-71.
127. Harrison RE, et al: Transforming growth factor-beta receptor mutations and pulmonary arterial hypertension in childhood. Circulation 2005, 111(4):435-41

128. Fujiwara $M$, et al: Implications of mutations of activin receptor-like kinase 1 gene (ALK1) in addition to bone morphogenetic protein receptor II gene (BMPR2) in children with pulmonary arterial hypertension. Circ J 2008, 72(1):127-33.

129. Smoot LB, et al: Clinical Features of Pulmonary Arterial Hypertension in Young People with an ALK1 Mutation and Hereditary Hemorrhagic Telangiectasia. Arch Dis Child 2009, 94(7):506-11.

130. Cracowski JL, et al: Évaluation pronostique de biomarqueurs dans I'hypertension artérielle pulmonaire. Rev Mal Respir 2004, 21(6 Pt 1):1137-43.

131. Morrell N, et al: Altered growth responses of pulmonary artery smooth muscle cells from patients with primary pulmonary hypertension to transforming growth factor-beta1 and bone morphogenetic proteins. Circulation 2001, 104:790-795.

132. Masri F, et al: Hyperproliferative apoptosis-resistant endothelial cells in idiopathic pulmonary arterial hypertension. Am J Physiol Lung Cell Mol Physiol 2007, 293(3):L548-54

133. Sztrymf B, et al: Genes and pulmonary arterial hypertension. Respiration 2007, 74(2):123-32

134. Girerd B, et al: Absence of influence of gender and BMPR2 mutation type on clinical phenotypes of pulmonary arterial hypertension. Respir Res 2010, 11:73.

135. West J, et al: Gene expression in BMPR2 mutation carriers with and without evidence of pulmonary arterial hypertension suggests pathways relevant to disease penetrance. BMC Med Genomics 2008, 1:45.

136. Austin ED, et al: Alterations in oestrogen metabolism: implications for higher penetrance of familial pulmonary arterial hypertension in females. Eur Respir J 2009, 34(5):1093-9.

137. O'Callaghan DS, et al: Treatment of pulmonary arterial hypertension with targeted therapies. Nat Rev Cardiol 2011, 8(9):526-38.

138. Stenmark KR, et al: Hypoxic activation of adventitial fibroblasts: role in vascular remodeling. Chest 2002, 122(6 Suppl):326S-334S.

139. Davie NJ, et al: Hypoxia-induced pulmonary artery adventitial remodeling and neovascularization: contribution of progenitor cells. Am J Physiol Lung Cell Mol Physiol 2004, 286(4):L668-78.

140. Cool CD, et al: Three-dimensional reconstruction of pulmonary arteries in plexiform pulmonary hypertension using cell-specific markers. Evidence for a dynamic and heterogeneous process of pulmonary endothelial cell growth. Am J Pathol 1999, 155(2):411-9.

141. Montani D, et al: C-Kit Positive Cells Accumulate in Remodeled Vessels of Idiopathic Pulmonary Arterial Hypertension. Am J Respir Crit Care Med 2011, 184(1):116-23.

142. Gambaryan N, et al: Circulating fibrocytes and pulmonary arterial hypertension. Eur Respir J 2012, 39(1):210-2.

143. Gambaryan N, et al: Targeting of c-kit + haematopoietic progenitor cells prevents hypoxic pulmonary hypertension. Eur Respir J 2011, 37(6):1392-9.

144. Kherbeck N, et al: The Role of Inflammation and Autoimmunity in the Pathophysiology of Pulmonary Arterial Hypertension. Clin Rev Allergy Immunol 2013, 44(1):31-8.

145. Balabanian $\mathrm{K}$, et al: CX(3)C chemokine fractalkine in pulmonary arterial hypertension. Am J Respir Crit Care Med 2002, 165(10):1419-25.

146. Itoh $\mathrm{T}$, et al: Increased plasma monocyte chemoattractant protein-1 level in idiopathic pulmonary arterial hypertension. Respirology 2006, 11(2):158-63.

147. Nicolls MR, et al: Autoimmunity and pulmonary hypertension: a perspective. Eur Respir J 2005, 26(6):1110-8.

148. Perros F, et al: Dendritic cell recruitment in lesions of human and experimental pulmonary hypertension. Eur Respir J 2007, 29(3):462-8.

149. Herve $P$, et al: Pathobiology of pulmonary hypertension. The role of platelets and thrombosis. Clin Chest Med 2001, 22(3):451-8.

150. Herve $P$, et al: Increased plasma serotonin in primary pulmonary hypertension. Am J Med 1995, 99:249-254.

151. Huertas $A$, et al: Leptin and regulatory T lymphocytes in idiopathic pulmonary arterial hypertension. Eur Respir J 2012, 40(4):895-904.

152. Perros F, et al: Pulmonary lymphoid neogenesis in idiopathic pulmonary arterial hypertension. Am J Respir Crit Care Med 2012, 185(3):311-21.

153. Humbert $M$, et al: Cellular and molecular pathobiology of pulmonary arterial hypertension. J Am Coll Cardiol 2004, 43(12 Suppl S):13S-24S. 
154. Christman BW, et al: An imbalance between the excretion of thromboxane and prostacyclin metabolites in pulmonary hypertension. N Engl J Med 1992, 327(2):70-5.

155. Montani $\mathrm{D}$, et al: Phosphodiesterase type 5 inhibitors in pulmonary arterial hypertension. Adv Ther 2009, 26(9):813-25.

156. Petkov $V$, et al: Vasoactive intestinal peptide as a new drug for treatment of primary pulmonary hypertension. J Clin Invest 2003, 111(9):1339-46.

157. Jeffery T, Morrell NW: Molecular and cellular basis of pulmonary vascular remodeling in pulmonary hypertension. Prog Cardiovasc Dis 2002, 45:173-202.

158. Giaid A, et al: Expression of endothelin-1 in the lungs of patients with pulmonary hypertension. N Engl J Med 1993, 328(24):1732-9.

159. Yuan XJ, et al: Attenuated $\mathrm{K}+$ channel gene transcription in primary pulmonary hypertension. Lancet 1998, 351(9104):726-7.

160. Yuan JX, et al: Dysfunctional voltage-gated $\mathrm{K}+$ channels in pulmonary artery smooth muscle cells of patients with primary pulmonary hypertension. Circulation 1998, 98(14):1400-6.

161. Weir EK, et al: Anorexic Agents Aminorex, Fenfluramine, and Dexfenfluramine Inhibit Potassium Current in Rat Pulmonary Vascular Smooth Muscle and Cause Pulmonary Vasoconstriction. Circulation 1996 94(9):2216-2220.

162. MacLean MR, et al: 5-hydroxytryptamine and the pulmonary circulation: receptors, transporters and relevance to pulmonary arterial hypertension. Br J Pharmacol 2000, 131(2):161-8.

163. Marcos $E$, et al: Serotonin transporter inhibitors protect against hypoxic pulmonary hypertension. Am J Respir Crit Care Med 2003, 168(4):487-93.

164. Keegan A, et al: Contribution of the 5-HT(1B) receptor to hypoxiainduced pulmonary hypertension: converging evidence using 5-HT (1B)-receptor knockout mice and the 5-HT(1B/1D)-receptor antagonist GR127935. Circ Res 2001, 89(12):1231-9.

165. Guilluy $C$, et al: Inhibition of RhoA/Rho kinase pathway is involved in the beneficial effect of sildenafil on pulmonary hypertension. $\mathrm{Br} J \mathrm{Pharmacol}$ 2005, 146(7):1010-8.

166. Nagaoka T, et al: Inhaled Rho kinase inhibitors are potent and selective vasodilators in rat pulmonary hypertension. Am J Respir Crit Care Med 2005, 171(5):494-9.

167. Guilluy $C$, et al: RhoA and Rho kinase activation in human pulmonary hypertension: role of 5-HT signaling. Am J Respir Crit Care Med 2009, 179(12):1151-8.

168. Semenza GL: HIF-1 and mechanisms of hypoxia sensing. Curr Opin Cell Biol 2001, 13(2):167-71.

169. Semenza GL: Involvement of hypoxia-inducible factor 1 in pulmonary pathophysiology. Chest 2005, 128(6 Suppl):592S-594S.

170. Tuder RM, et al: Expression of angiogenesis-related molecules in plexiform lesions in severe pulmonary hypertension: evidence for a process of disordered angiogenesis. J Pathol 2001, 195(3):367-74.

171. Remillard CV, Yuan JX: High altitude pulmonary hypertension: role of $\mathrm{K}+$ and Ca2+ channels. High Alt Med Biol 2005, 6(2):133-46.

172. Cool CD, et al: Pathogenesis and evolution of plexiform lesions in pulmonary hypertension associated with scleroderma and human immunodeficiency virus infection. Hum Pathol 1997, 28(4):434-42.

173. Pietra GG, et al: Pathologic assessment of vasculopathies in pulmonary hypertension. J Am Coll Cardiol 2004, 43(12 Suppl S):25S-32S.

174. Bjornsson J, Edwards WD: Primary pulmonary hypertension: a histopathologic study of 80 cases. Mayo Clin Proc 1985, 60(1):16-25.

175. Heath D, Edwards JE: The pathology of hypertensive pulmonary vascular disease; a description of six grades of structural changes in the pulmonary arteries with special reference to congenital cardiac septal defects. Circulation 1958, 18(4 Part 1):533-47.

176. Dorfmuller $P$, et al: Inflammation in pulmonary arterial hypertension. Eur Respir J 2003, 22(2):358-63.

177. Dorfmuller $P$, et al: Chemokine RANTES in severe pulmonary arterial hypertension. Am J Respir Crit Care Med 2002, 165(4):534-9.

178. Dorfmuller $P$, et al: Fibrous remodeling of the pulmonary venous system in pulmonary arterial hypertension associated with connective tissue diseases. Hum Pathol 2007, 38(6):893-902.

179. Overbeek MJ, et al: Pulmonary arterial hypertension in limited cutaneous systemic sclerosis: a distinctive vasculopathy. Eur Respir J 2009, 34(2):371-9.
180. Golde DW, et al: Occult pulmonary haemorrhage in leukaemia. Br Med J 1975, 2(5964):166-8.

181. Tron V, et al: Pulmonary capillary hemangiomatosis. Hum Pathol 1986, 17(11):1144-50.

182. Runo JR, et al: Pulmonary veno-occlusive disease caused by an inherited mutation in bone morphogenetic protein receptor II. Am J Respir Crit Care Med 2003, 167(6):889-94

183. Barst RJ, et al: Diagnosis and differential assessment of pulmonary arterial hypertension. J Am Coll Cardiol 2004, 43(12 Suppl S):40S-47S.

184. Elliott CG, et al: Pulmonary veno-occlusive disease associated with severe reduction of single-breath carbon monoxide diffusing capacity. Respiration 1988, 53(4):262-6.

185. Groepenhoff $\mathrm{H}$, et al: Exercise testing to estimate survival in pulmonary hypertension. Med Sci Sports Exerc 2008, 40(10):1725-32.

186. Wensel $R$, et al: Assessment of survival in patients with primary pulmonary hypertension: importance of cardiopulmonary exercise testing. Circulation 2002, 106(3):319-24.

187. McQuillan BM, et al: Clinical correlates and reference intervals for pulmonary artery systolic pressure among echocardiographically normal subjects. Circulation 2001, 104(23):2797-802

188. Tunariu $N$, et al: Ventilation-perfusion scintigraphy is more sensitive than multidetector CTPA in detecting chronic thromboembolic pulmonary disease as a treatable cause of pulmonary hypertension. J NuCl Med 2007, 48(5):680-4.

189. Ley S, et al: Diagnostic performance of state-of-the-art imaging techniques for morphological assessment of vascular abnormalities in patients with chronic thromboembolic pulmonary hypertension (CTEPH). Eur Radiol 2012, 22(3):607-16.

190. Marcus JT, et al: Interventricular mechanical asynchrony in pulmonary arterial hypertension: left-to-right delay in peak shortening is related to right ventricular overload and left ventricular underfilling. J Am Coll Cardiol 2008, 51(7):750-7.

191. Haddad F, et al: Right ventricular function in cardiovascular disease, part I: Anatomy, physiology, aging, and functional assessment of the right ventricle. Circulation 2008, 117(11):1436-48.

192. Galie N, et al: Guidelines for the diagnosis and treatment of pulmonary hypertension: The Task Force for the Diagnosis and Treatment of Pulmonary Hypertension of the European Society of Cardiology (ESC) and the European Respiratory Society (ERS), endorsed by the International Society of Heart and Lung Transplantation (ISHLT). Eur Heart J 2009, 30(20):2493-537.

193. van Wolferen SA, et al: Prognostic value of right ventricular mass, volume, and function in idiopathic pulmonary arterial hypertension. Eur Heart J 2007, 28(10):1250-7.

194. Naeije R: Hepatopulmonary syndrome and portopulmonary hypertension. Swiss Med Wkly 2003, 133(11-12):163-9.

195. Hoeper MM, et al: Complications of right heart catheterization procedures in patients with pulmonary hypertension in experienced centers. J Am Coll Cardiol 2006, 48(12):2546-52.

196. Benza RL, et al: The REVEAL Registry risk score calculator in patients newly diagnosed with pulmonary arterial hypertension. Chest 2012, 141(2):354-62

197. Sitbon O, Humbert M, Simonneau G: Primary pulmonary hypertension: Current therapy. Prog Cardiovasc Dis 2002, 45(2):115-28.

198. Bonnin M, et al: Severe pulmonary hypertension during pregnancy: mode of delivery and anesthetic management of 15 consecutive cases. Anesthesiology 2005, 102(6):1133-7. discussion 5A-6A.

199. Price LC, et al: Non-cardiothoracic non-obstetric surgery in mildmoderate pulmonary hypertension: Perioperative management of 28 consecutive individual cases. Eur Respir J 2010, 35(6):1294-302.

200. Provencher $S$, et al: Heart rate responses during the 6-minute walk test in pulmonary arterial hypertension. Eur Respir J 2006, 27(1):114-20.

201. Sitbon O, et al: Long-term intravenous epoprostenol infusion in primary pulmonary hypertension: prognostic factors and survival. J Am Coll Cardiol 2002, 40(4):780-8.

202. Fuster $V$, et al: Primary pulmonary hypertension: natural history and the importance of thrombosis. Circulation 1984, 70(4):580-7.

203. Rich S, Kaufmann E, Levy PS: The effect of high doses of calciumchannel blockers on survival in primary pulmonary hypertension. N Engl J Med 1992, 327(2):76-81. 
204. Rich S, et al: The short-term effects of digoxin in patients with right ventricular dysfunction from pulmonary hypertension. Chest 1998, 114(3):787-92.

205. Sitbon O, et al: Long-term response to calcium channel blockers in idiopathic pulmonary arterial hypertension. Circulation 2005, 111(23):3105-11.

206. Moncada S, et al: An enzyme isolated from arteries transforms prostaglandin endoperoxides to an unstable substance that inhibits platelet aggregation. Nature 1976, 263(5579):663-5.

207. Rubin $\sqcup$, et al: Treatment of primary pulmonary hypertension with continuous intravenous prostacyclin (epoprostenol). Results of a randomized trial. Ann Intern Med 1990, 112(7):485-91.

208. O'Callaghan DS, et al: Treatment of pulmonary arterial hypertension with targeted therapies. Nat Rev Cardiol 2011, 8(9):526-38.

209. Higenbottam T, et al: Long-term treatment of primary pulmonary hypertension with continuous intravenous epoprostenol (prostacyclin). Lancet 1984, 1(8385):1046-7.

210. Robbins IM, et al: A survey of diagnostic practices and the use of epoprostenol in patients with primary pulmonary hypertension. Chest 1998, 114(5):1269-75.

211. Barst RJ, et al: A comparison of continuous intravenous epoprostenol (prostacyclin) with conventional therapy for primary pulmonary hypertension. The Primary Pulmonary Hypertension Study Group. N Engl J Med 1996, 334(5):296-302.

212. Badesch DB, et al: Continuous intravenous epoprostenol for pulmonary hypertension due to the scleroderma spectrum of disease. A randomized, controlled trial. Ann Intern Med 2000, 132(6):425-34.

213. Barst $R$, et al: Survival in primary pulmonary hypertension with long-term continuous intravenous prostacyclin. Ann Intern Med 1994, 121(6):409-15.

214. McLaughlin W, Shillington A, Rich S: Survival in primary pulmonary hypertension: the impact of epoprostenol therapy. Circulation 2002, 106(12):1477-82.

215. Rosenzweig EB, Kerstein D, Barst RJ: Long-term prostacyclin for pulmonary hypertension with associated congenital heart defects. Circulation 1999, 99(14):1858-65.

216. Nunes $\mathrm{H}$, et al: Prognostic factors for survival in human immunodeficiency virus-associated pulmonary arterial hypertension. Am J Respir Crit Care Med 2003, 167(10):1433-9.

217. Cabrol S, et al: Intravenous epoprostenol in inoperable chronic thromboembolic pulmonary hypertension. J Heart Lung Transplant 2007, 26(4):357-62.

218. McLaughlin W, et al: Reduction in pulmonary vascular resistance with long-term epoprostenol (prostacyclin) therapy in primary pulmonary hypertension. N Engl J Med 1998, 338(5):273-7.

219. Shapiro SM, et al: Primary pulmonary hypertension: improved long-term effects and survival with continuous intravenous epoprostenol infusion. J Am Coll Cardiol 1997, 30(2):343-9.

220. Laliberte $K$, et al: Pharmacokinetics and steady-state bioequivalence of treprostinil sodium (Remodulin) administered by the intravenous and subcutaneous route to normal volunteers. J Cardiovasc Pharmacol 2004, 44(2):209-14.

221. Simonneau $G$, et al: Continuous subcutaneous infusion of treprostinil, a prostacyclin analogue, in patients with pulmonary arterial hypertension: a double-blind, randomized, placebo-controlled trial. Am J Respir Crit Care Med 2002, 165(6):800-4.

222. McLaughlin W, et al: Addition of inhaled treprostinil to oral therapy for pulmonary arterial hypertension: a randomized controlled clinical trial. J Am Coll Cardiol 2010, 55(18):1915-22.

223. Olschewski $\mathrm{H}$, et al: Inhaled iloprost for severe pulmonary hypertension. N Engl J Med 2002, 347(5):322-9.

224. Hoeper MM, et al: Long-term treatment of primary pulmonary hypertension with aerosolized iloprost, a prostacyclin analogue. $N$ Engl J Med 2000, 342(25):1866-70

225. Channick RN, et al: Effects of the dual endothelin-receptor antagonist bosentan in patients with pulmonary hypertension: a randomised placebo-controlled study. Lancet 2001, 358(9288):1119-23.

226. Rubin $L$, et al: Bosentan therapy for pulmonary arterial hypertension. N Engl J Med 2002, 346(12):896-903.

227. Humbert M, et al: Combination of bosentan with epoprostenol in pulmonary arterial hypertension: BREATHE-2. Eur Respir J 2004, 24(3):353-9.

228. Galie N, et al: Treatment of patients with mildly symptomatic pulmonary arterial hypertension with bosentan (EARLY study): a double-blind, randomised controlled trial. Lancet 2008, 371(9630):2093-100.
229. Sitbon O, et al: Effects of the dual endothelin receptor antagonist bosentan in patients with pulmonary arterial hypertension: a 1-year follow-up study. Chest 2003, 124(1):247-54.

230. McLaughlin W, et al: Survival with first-line bosentan in patients with primary pulmonary hypertension. Eur Respir J 2005, 25(2):244-9.

231. Sitbon O, et al: Survival in patients with class III idiopathic pulmonary arterial hypertension treated with first line oral bosentan compared with an historical cohort of patients started on intravenous epoprostenol. Thorax 2005, 60(12):1025-30.

232. Galie N, et al: Ambrisentan for the treatment of pulmonary arterial hypertension: results of the ambrisentan in pulmonary arterial hypertension, randomized, double-blind, placebo-controlled, multicenter, efficacy (ARIES) study 1 and 2. Circulation 2008, 117(23):3010-9.

233. Klinger JR, et al: Long-term pulmonary hemodynamic effects of ambrisentan in pulmonary arterial hypertension. Am J Cardio/ 2011, 108(2):302-7.

234. Ghofrani $H A$, et al: Sildenafil for treatment of lung fibrosis and pulmonary hypertension: a randomised controlled trial. Lancet 2002, 360(9337):895-900.

235. Schermuly RT, et al: Chronic sildenafil treatment inhibits monocrotalineinduced pulmonary hypertension in rats. Am J Respir Crit Care Med 2004, 169(1):39-45.

236. Galie N, et al: Sildenafil citrate therapy for pulmonary arterial hypertension. N Engl J Med 2005, 353(20):2148-57.

237. Galie N, et al: Tadalafil therapy for pulmonary arterial hypertension. Circulation 2009, 119(22):2894-903.

238. Barst $\mathrm{R}$, et al: Tadalafil monotherapy and as add-on to background bosentan in patients with pulmonary arterial hypertension. J Heart Lung Transplant 2011, 30(6):632-43.

239. Simonneau $G$, et al: Addition of sildenafil to long-term intravenous epoprostenol therapy in patients with pulmonary arterial hypertension: a randomized trial. Ann Intern Med 2008, 149(8):521-30.

240. McLaughlin W, et al: Randomized study of adding inhaled iloprost to existing bosentan in pulmonary arterial hypertension. Am J Respir Crit Care Med 2006, 174(11):1257-63.

241. Hoeper MM, et al: Bosentan treatment in patients with primary pulmonary hypertension receiving nonparenteral prostanoids. Eur Respir J 2003, 22(2):330-4.

242. Ghofrani HA, et al: Oral sildenafil as long-term adjunct therapy to inhaled iloprost in severe pulmonary arterial hypertension. J Am Coll Cardiol 2003, 42(1):158-64.

243. Gomberg-Maitland M, et al: Efficacy and safety of sildenafil added to treprostinil in pulmonary hypertension. Am J Cardiol 2005, 96(9):1334-6.

244. Hoeper MM, et al: Combination therapy with bosentan and sildenafil in idiopathic pulmonary arterial hypertension. Eur Respir J 2004, 24(6):1007-10.

245. Mathai SC, et al: Addition of sildenafil to bosentan monotherapy in pulmonary arterial hypertension. Eur Respir J 2007, 29(3):469-75.

246. Rubin L, et al: Effect of Macitentan on Morbidity and Mortality in Pulmonary Arterial Hypertension (PAH): Results From the SERAPHIN Trial. Chest 2012, 142:1026A-1026A. doi:10.1378/chest.1456207.

247. Iglarz $M$, et al: Pharmacology of macitentan, an orally active tissuetargeting dual endothelin receptor antagonist. J Pharmacol Exp Ther 2008, 327(3):736-45.

248. Sidharta PN, et al: Macitentan: entry-into-humans study with a new endothelin receptor antagonist. Eur J Clin Pharmacol 2011, 67(10):977-84.

249. Jing ZC, et al: Vardenafil in pulmonary arterial hypertension: a randomized, double-blind, placebo-controlled study. Am J Respir Crit Care Med 2011, 183(12):1723-9.

250. Ghofrani HA, Grimminger F: Soluble guanylate cyclase stimulation: an emerging option in pulmonary hypertension therapy. Eur Respir Rev 2009, 18(111):35-41.

251. Grimminger F, et al: First acute haemodynamic study of soluble guanylate cyclase stimulator riociguat in pulmonary hypertension. Eur Respir J 2009, 33(4):785-92.

252. Ghofrani HA, et al: Riociguat for chronic thromboembolic pulmonary hypertension and pulmonary arterial hypertension: a phase II study. Eur Respir J 2010, 36(4):792-9.

253. Schermuly RT, et al: Riociguat for the treatment of pulmonary hypertension. Expert Opin Investig Drugs 2011, 20(4):567-76.

254. Ghio S, et al: Left ventricular systolic dysfunction associated with pulmonary hypertension riociguat trial (LEPHT): rationale and design. Eur J Heart Fail 2012, 14(8):946-53.

255. Hoeper MM, et al: Riociguat for interstitial lung disease and pulmonary hypertension: a pilot trial. Eur Respir J 2013, 41(4):853-60. 


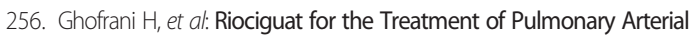
Hypertension. N Engl J Med 2013, 369(4):330-40.

257. Asaki T, et al: Structure-activity studies on diphenylpyrazine derivatives: a novel class of prostacyclin receptor agonists. Bioorg Med Chem 2007, 15(21):6692-704

258. Kuwano K, et al: 2-[4-[(5,6-diphenylpyrazin-2-yl)(isopropyl)amino]butoxy]-N(methylsulfonyl)acetam ide (NS-304), an orally available and long-acting prostacyclin receptor agonist prodrug. J Pharmacol Exp Ther 2007, 322(3):1181-8.

259. Kuwano $\mathrm{K}$, et al: A long-acting and highly selective prostacyclin receptor agonist prodrug, 2-\{4-[(5,6-diphenylpyrazin-2-yl)(isopropyl)amino]butoxy\}-N(methylsulfonyl)acetam ide (NS-304), ameliorates rat pulmonary hypertension with unique relaxant responses of its active form, $\{4-[(5,6-$ diphenylpyrazin-2-yl) (isopropyl)amino]butoxy\}acetic acid (MRE-269), on rat pulmonary artery. J Pharmacol Exp Ther 2008, 326(3):691-9.

260. Morrison $\mathrm{K}$, et al: Differential effects of selexipag and prostacyclin analogs in rat pulmonary artery. J Pharmacol Exp Ther 2012, 343(3):547-55.

261. Simonneau G, et al: Selexipag: an oral, selective prostacyclin receptor agonist for the treatment of pulmonary arterial hypertension. Eur Respir J 2012, 40(4):874-80

262. NIH: ClinicalTrials.gov. ACT-293987 in pulmonary arterial hypertension [online] 2011.

263. Barst RJ: PDGF signaling in pulmonary arterial hypertension. J Clin Invest 2005, 115(10):2691-4.

264. Perros F, et al: Platelet-derived growth factor expression and function in idiopathic pulmonary arterial hypertension. Am J Respir Crit Care Med 2008, 178(1):81-8.

265. Panos RJ, Baker SK: Mediators, cytokines, and growth factors in liver-lung interactions. Clin Chest Med 1996, 17(1):151-69.

266. Schermuly RT, et al: Reversal of experimental pulmonary hypertension by PDGF inhibition. J Clin Invest 2005, 115(10):2811-21.

267. Ghofrani H, et al: Imatinib in pulmonary arterial hypertension patients with inadequate response to established therapy. Am J Respir Crit Care Med 2010, 182(9):1171-7.

268. Hoeper MM, et al: Imatinib mesylate as add-on therapy for pulmonary arterial hypertension: results of the randomized IMPRES study. Circulation 2013, 127(10):1128-38.

269. Kerkela R, et al: Cardiotoxicity of the cancer therapeutic agent imatinib mesylate. Nat Med 2006, 12(8):908-16.

270. McLaughlin W, et al: Prognosis of pulmonary arterial hypertension: ACCP evidence-based clinical practice guidelines. Chest 2004, 126(1 Suppl):785-925.

271. Sandoval J, et al: Graded balloon dilation atrial septostomy in severe primary pulmonary hypertension. A therapeutic alternative for patients nonresponsive to vasodilator treatment. J Am Coll Cardiol 1998, 32(2):297-304

272. Rothman A, et al: Atrial septostomy as a bridge to lung transplantation in patients with severe pulmonary hypertension. Am J Cardiol 1999, 84(6):682-6.

273. Kerstein $D$, et al: Blade balloon atrial septostomy in patients with severe primary pulmonary hypertension. Circulation 1995, 91(7):2028-35.

274. Kurzyna M, et al: Atrial septostomy in treatment of end-stage right heart failure in patients with pulmonary hypertension. Chest 2007, 131(4):977-83.

275. Hosenpud JD, et al: The Registry of the International Society for Heart and Lung Transplantation: eighteenth Official Report-2001. J Heart Lung Transplant 2001, 20(8):805-15.

276. Levine SM, et al: Single lung transplantation for primary pulmonary hypertension. Chest 1990, 98(5):1107-15.

277. Pielsticker EJ, Martinez FJ, Rubenfire M: Lung and heart-lung transplant practice patterns in pulmonary hypertension centers. I Heart Lung Transplant 2001, 20(12):1297-304.

278. Mendeloff EN, et al: Lung transplantation for pulmonary vascular disease. Ann Thorac Surg 2002, 73(1):209-17. discussion 217-9.

279. Reitz BA, et al: Heart-lung transplantation: successful therapy for patients with pulmonary vascular disease. N Engl J Med 1982, 306(10):557-64

doi:10.1186/1750-1172-8-97

Cite this article as: Montani et al.: Pulmonary arterial hypertension.

Orphanet Journal of Rare Diseases 2013 8:97.

\section{Submit your next manuscript to BioMed Central and take full advantage of:}

- Convenient online submission

- Thorough peer review

- No space constraints or color figure charges

- Immediate publication on acceptance

- Inclusion in PubMed, CAS, Scopus and Google Scholar

- Research which is freely available for redistribution
C Biomed Central 